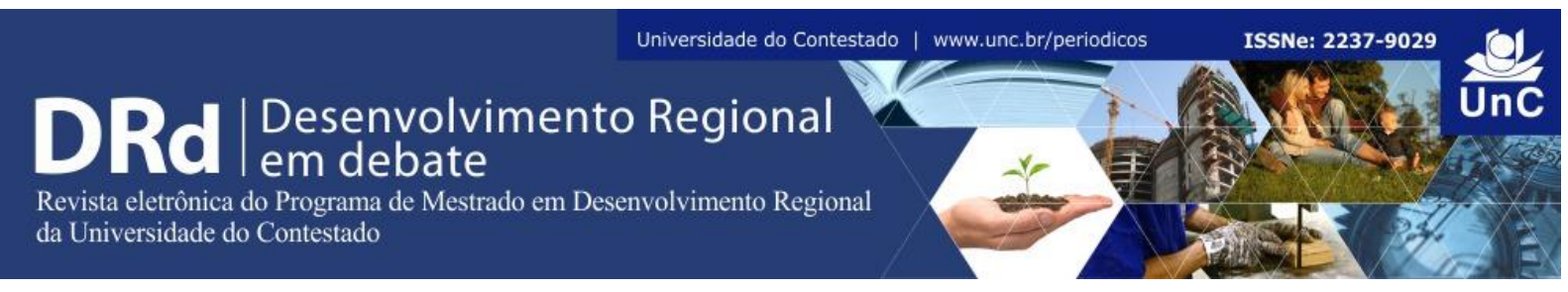

\title{
CONJUNTURA DO DESENVOLVIMENTO REGIONAL DOS MUNICÍPIOS DO ESTADO DO TOCANTINS ${ }^{1}$
}

\author{
Nilton Marques de Oliveira ${ }^{2}$ \\ Moacir Piffer ${ }^{3}$
}

\begin{abstract}
RESUMO
O objetivo deste artigo foi analisar a conjuntura e o perfil do desenvolvimento social e econômico regional dos municípios do Estado do Tocantins entre 2000 e 2010. O método utilizado foi o Índice de Desenvolvimento Regional (IDR), com base em variáveis sociais e econômicas. O Aporte teórico foi o institucionalista, tendo como expoente os trabalhos de North sobre a Base de Exportação e o Ambiente Institucional. Os resultados apontaram que o desenvolvimento regional no Tocantins não se deu de forma homogênea no tempo e no espaço. A construção da BR-153 fez os elos com as cidades do seu corredor e com seus corredores menores, destacando as cidades que estão instaladas ao longo dessa rodovia. Isso implicou expansão, ocupação de novas fronteiras agrícolas, reprodução e ampliação do capital, no entanto, ocorreram profundos desequilíbrios sociais e econômicos em quase todos os municípios, com exceção dos municípios de Palmas, Araguaína e Gurupi. A partir de 2010, constatou-se melhora sensível do IDR, que se deve, sobretudo, a indicadores sociais, como, por exemplo, queda da taxa de pobreza, aumento dos gastos em saúde, em saneamento e em educação. Em relação aos indicadores econômicos, um dos principais fatores foi a criação de novos postos de trabalhos na área de serviços, de comércio e de administração pública, verificou-se, também, aumento do PIB municipal.
\end{abstract}

Palavras-Chave: Desenvolvimento Regional. Desigualdades sociais e econômicas. Economia do Tocantins

\footnotetext{
${ }^{1}$ Esta pesquisa teve apoio financeiro da Capes, na modalidade prodoutoral e na modalidade "Novos Pesquisadores" UFT/PROPESQ.

${ }^{2}$ Doutorando em Desenvolvimento Regional e Agronegócio pela Universidade Estadual do Oeste do Paraná UNIOESTE, Campus de Toledo -PR. Mestre em Economia Aplicada pela Universidade Federal de Viçosa UFV. Professor do Curso de Ciências Econômicas da Universidade Federal do Tocantins - UFT. Palmas - TO, Brasil. E-mail: niltonmarques@uft.edu.br

${ }^{3}$ Doutor em Desenvolvimento Regional pela Universidade de Santa Cruz do Sul (UNISC). Mestre em Desenvolvimento Econômico pela Universidade Federal do Paraná (UFPR). Professor do Programa de PósGraduação em Desenvolvimento Regional e Agronegócio da Universidade Estadual do Oeste do Paraná UNIOESTE, Campus de Toledo - PR. Professor visitante da Escuela Venezolana de Planificación. Toledo -PR, Brasil. E-mail: mopiffer@yahoo.com.br.
}

DRd - Desenvolvimento Regional em debate (ISSNe 2237-9029)

v. 6, n. 3, p. 32-61, nov. 2016. 


\title{
CONTEXT OF REGIONAL DEVELOPMENT OF MUNICIPALITIES OF THE TOCANTINS STATE, BRAZIL
}

\begin{abstract}
This study aimed to analyze the context and the profile of the regional social and economic development of the municipalities of Tocantins State, Brazil, from 2000 to 2010. The Regional Development Index (RDI) method was used, on the basis of social and economic variables. Institutional Theory was the support with the exponent of the North's work on the Exporting Base and the Institutional Environment. Results indicate that the regional development in Tocantins did not occur homogeneously in time and space. The construction of the BR-153 highway establishes links among surrounding cities, highlighting the cities that are located along this highway. This meant expansion and occupation of new agricultural frontiers, reproduction and expansion of financial capital; however, there were deep social and economic imbalances in almost all municipalities, except for Palmas, Araguaína, and Gurupi municipalities. From 2010, it was found sensitive improvement of Rural Development Index (RDI), which is due mainly to social indicators, such as poverty rate fall, increased spending on health, sanitation, and education. With regard to economic indicators, one of the main factors was the creation of new job posts in services, trade, and public administration areas; there was also increase in the municipal Gross Domestic Product (GDP).
\end{abstract}

Keywords: Regional Development. Social and economic inequalities. Tocantins economy.

\section{INTRODUÇÃO}

Este artigo tem por objetivo analisar a conjuntura e o perfil do desenvolvimento social e econômico regional dos municípios do Tocantins nos anos de 2000 e 2010. O grau de desenvolvimento socioeconômico regional pode ser estimado pelo Índice de Desenvolvimento Regional (IDR), tendo como referência os estudos de Gualda (1995). Para tanto, foi feita uma análise dos indicadores econômicos e sociais dos 139 municípios tocantinense e como eles afetaram o Índice de Desenvolvimento Regional (IDR) nos municípios do Estado do Tocantins.

O Estado do Tocantins, criado em 05 de outubro de 1988, tem uma área de 277.620,9 $\mathrm{km}^{2}$, participa com 7\% em relação à área da região Norte (3.869.637) e 3,3\% do território nacional, sendo Palmas a capital do estado. Limita-se ao norte com os Estados do Maranhão e do Pará; ao sul com o Estado de Goiás; ao leste com os Estados do Maranhão, do Piauí e da Bahia; e ao oeste com os Estados do Pará e do Mato Grosso. Em território tocantinense, as distâncias máximas são de $899,5 \mathrm{~km}$ na direção norte-sul, e entre os pontos extremos lesteoeste são 615,4 km. O estado compreende 139 municípios (IBGE, 2011).

De acordo com o Censo Demográfico do IBGE (2010), Tocantins tem uma população de $1.383,3$ mil habitantes, o que representa $0,73 \%$ de população do país e $8,82 \%$ da população

DRd - Desenvolvimento Regional em debate (ISSNe 2237-9029) 
da região Norte. A densidade demográfica é de $4,98 \mathrm{hab} / \mathrm{km}^{2}$ e a composição demográfica é $79 \%$ urbana e $31 \%$ rural.

O crescimento econômico e a urbanização do Tocantins, de fato, só vieram a acontecer a partir da primeira década do século XXI. A população do Estado teve um crescimento médio de 22,5\%, no período de 2000 a 2010, e em relação ao Produto Interno Bruto, foi o Estado que mais cresceu no acumulado entre 2002 e 2010, 74,2\% em termos absolutos (IBGE 2012). Quanto à criação de emprego formal, em 2000, o Estado contava com 106.040, em 2013, esse número passou para 257.536, um crescimento de mais 142\% (BRASIL. MTE, 2014).

O setor produtivo tem passado por um processo de expansão que poderá fazer com que assuma uma posição mais relevante no cenário nacional nos próximos anos. O Estado apresenta grande desigualdade social e econômica entre seus municípios, exceto Palmas, Araguaína e Gurupi. Desde sua criação, o Tocantins tem melhorado seus indicadores sociais e econômicos, com investimentos nas áreas de saúde, educação e nos setores primário, secundário e terciário.

Os dados citados do Estado do Tocantins são de crescimento econômico, porém o desenvolvimento regional envolve um conjunto mais amplo de variáveis, desde econômicas, sociais, ambientais, culturais e institucionais. Conhecendo os potenciais produtivos e sabendo das disparidades econômicas e sociais de todos os municípios, podem-se subsidiar políticas de desenvolvimento local com o objetivo de alavancar o potencial de cada localidade, principalmente dos municípios menos desenvolvidos, com o intuito de reduzir as desigualdades inter e intramunicipais do Tocantins.

Dessa forma, alguns questionamentos são levantados: Quais municípios apresentam desenvolvimento social e econômico satisfatório? Qual o perfil das desigualdades sociais e econômicas dos municípios do Tocantins? Assim, este artigo aponta alguns elementos para compreender os entraves que impedem maior desenvolvimento nos municípios considerados retardatários no processo de desenvolvimento regional do Tocantins.

Isto posto, este artigo, além desta introdução, está divido em mais quatro seções. $\mathrm{Na}$ primeira seção, é apresentado o aporte teórico; na segunda, o Índice de Desenvolvimento Regional (IDR); na terceira, são apresentados e discutidos os principais resultados; e por fim, as considerações finais.

\section{TERRITÓRIO E A TEORIA DA BASE DE EXPORTAÇÃO: AMBIENTE INSTITUCIONAL E GOVERNANÇA}

Tendo com enfoque o desenvolvimento regional do Tocantins, numa vertente institucional, esta pesquisa aborda também o conceito de desenvolvimento territorial. Segundo Haesbaert (2009), o território surge como o espaço concreto, com seus atributos naturais e socialmente construídos, apropriado e ocupado por um grupo social. Para Haesbaert (1997), Bourdieu (1989), Barbosa (1998) e Sposito (2000), os conceitos de território vinculam-se aos sentimentos e aos simbolismos atribuídos aos lugares. 
O território é um espaço definido e delimitado por e pela relação de poder, indo além da abordagem política, haja vista que congrega aspectos culturais dos múltiplos territórios, os quais incluem atores sociais, políticos e econômicos. O enfoque que Sposito $(2000,2004)$ dá ao conceito de território diz respeito à territorialidade e sua apreensão, mesmo que sua abordagem carregue forte conotação cultural. A territorialidade, nesse caso, pertence ao mundo dos sentidos e, portanto, da cultura, das interações, cuja referência básica é a pessoa e sua capacidade de se localizar e se deslocar.

A ocupação do território é geradora de raízes e de identidade. Um grupo não pode mais ser compreendido sem seu território e a identidade social e cultural das pessoas. $\mathrm{O}$ território não deixa de ser importante, não apenas por ser espaço próprio do Estado, mas também de diferentes atores sociais, que manifestam seu poder sobre uma área específica, no caso desta pesquisa, o Estado do Tocantins, estando essa manifestação de poder ligada ao ambiente histórico e institucional (RAFFESTIN, 1993).

O território visto nessa perspectiva, é um espaço onde se projetou um trabalho, seja de energia ou de informação e que, por consequência, revela reações marcadas pelo poder. Nesse ponto, enfatiza-se uma categoria essencial para a compreensão do território que é o poder exercido por pessoas ou grupos. Poder e território, embora conceitos construídos, cada um, com sua autonomia, doravante vão ser enfocados juntos para a consolidação do conceito de território (SPOSITO, 2000; SAQUET, 2003).

Para Raffestin (1993), a ação das pessoas ou grupos no exercício do poder pode ser uma interação política, econômica, social e cultural, que resulta de jogos de oferta e de procura, que provém dos indivíduos e/ou dos grupos. "Isto conduz a sistemas de malhas, de nós e redes que se imprimem no espaço e que constitui de algum modo o território" (RAFFESTIN, 1993, p.150).

Todavia, sobre a discussão sobre território, Moraes (2005) argumenta que a formação territorial se articula numa dialética entre a construção material e a construção simbólica do espaço, que unifica num mesmo movimento processos econômicos, políticos e culturais. $\mathrm{O}$ território material é referência para formas de consciência e representação, cujos discursos retroagem no processo de produção material, com a apropriação e exploração dos lugares. $\mathrm{O}$ território é concomitante, uma construção militar, política, econômica, jurídica e ainda uma construção ideológica, que fundamenta uma identidade social e uma psicologia coletiva.

O território passa ser visto como resultado histórico do relacionamento da sociedade com o espaço, o qual só pode ser desvendado por meio do estudo de sua gênese e desenvolvimento (MORAES, 2005).

Bourdieu (1989, p. 7-8) define território como poder simbólico como "esse poder invisível o qual só pode ser exercido com a cumplicidade daqueles que não querem saber que lhe estão sujeitos ou mesmo que o exercem". O poder simbólico é um poder quase mágico que permite obter o equivalente daquilo que é obtido pela força. Para o autor supracitado, esse poder simbólico pode constituir uma identidade territorial, ou seja, um conjunto concatenado de representações socioespaciais que dão certa homogeneidade, atribuindo coesão e força (simbólica) ao grupo que ali vive, que com ele se identifica.

Desenvolvimento regional compreende uma análise de fatores sociais e econômicos no interior de uma região, fatores esses que compõem a mobilidade espacial do capital, do 
trabalho e das inovações tecnológicas. Tais fatores, quando bem empregados em uma determinada região, podem reduzir ou acelerar as desigualdades regionais. $\mathrm{O}$ desenvolvimento regional constitui um processo de transformação social, econômico, cultural e político. Essas transformações são questões centrais para se entender a evolução da dinâmica dos setores produtivos de uma região. As teorias de desenvolvimento regional estão próximas da posição da corrente institucionalista, foco deste artigo. As instituições são resultado de um processo seletivo e adaptativo que modela os tipos prevalecentes ou dominantes de atitudes ou aptidões (VEBLEN, 1988).

North (1990) argumenta que os modelos institucionais tendem a se autorreforçar, mesmo quando são socialmente ineficientes. É mais fácil aos indivíduos se adaptar às regras já existentes do que tentar modificá-las. Quando o desenvolvimento de uma região toma determinada direção, a cultura organizacional, os costumes e os modelos mentais do mundo social reforçam essa trajetória, ou seja, impulsionam esse desenvolvimento a se mover numa mesma direção.

A teoria da base de exportação teve como pioneiro os trabalhos de North (1977a) para explicar com se dá o processo de desenvolvimento econômico via base de exportação das atividades produtivas. Esse estudo é considerado o primeiro a dar uma formulação do conceito de base aplicado ao contexto regional. A teoria da base de exportação possibilita a forma mais simples de modelo de renda regional, estando sua importância no fato de servir como estrutura teórica para estudos empíricos de regiões (RICHARDSON, 1975). A teoria da base de exportação explica essas relações inter-regionais que envolvem o fluxo de mercadorias, de pessoas e de serviços, bem como avalia as implicações desses fluxos entre a região e o restante da economia mundial.

A segunda fase do pensamento de North $(1990,1991,1994)$ trata do papel das instituições na evolução histórica e no desenvolvimento das sociedades. Nessa fase, o autor se preocupa em explicar como as instituições atuam no desempenho econômico e na organização do processo produtivo das sociedades.

North $(1991,1994)$ se posiciona da seguinte forma quanto se trata de falar sobre desenvolvimento econômico, para o autor deve-se levar em conta o conhecimento econômico histórico e teórico. Sua análise recai sobre o conceito histórico, e dando ênfase ao ambiente institucional e ao conceito do path dependence ${ }^{4}$, explica os resultados econômicos alcançados em função de decisões passadas, do que das condições presentes.

As instituições são o principal regulador das atividades e interações humanas. North $(1991,1994)$ expõe em sua obra um marco analítico para explicar como as instituições e as mudanças institucionais afetam a economia. As instituições existem devido à incerteza que resulta da interação humana. North parte da premissa de que o mercado acarreta custos na economia, segundo Coase (1937), e que a diminuição de tais custos decorre da existência de instituições. Dessa forma, as instituições reduzem incertezas porque proporcionam uma estrutura à vida diária, constituindo um processo para a interação humana, que inclui todo tipo de limitação que as pessoas criam para tornar possível a vida em sociedade, com base no respeito às regras (AREND; CARIO, 2005).

\footnotetext{
${ }^{4}$ A ideia central do path depencence expressa o caráter irreversível e histórico do sistema capitalista, significa uma ligação do passado com o presente e o futuro, segundo Noth (1993), as instituições apresentam características históricas determinadas. Ver North (1990, 1993); Putnam (2007).
}

DRd - Desenvolvimento Regional em debate (ISSNe 2237-9029)

v. 6 , n. 3, p. 32-61, nov. 2016. 
Exposto dessa forma, percebe-se que as instituições figuram como os limites estabelecidos pelo homem, a fim de estruturar sua própria interação. Na concepção de Cárdenas e Ojeda (2002), as regras formais ou intencionais são criadas com um propósito especifico. As regras formais incluem questões relacionadas à política, questões jurídicas, econômicas e contratuais. Já as informais nascem do próprio indivíduo de uma ação coletiva, herdadas de geração em geração, constituindo nossos costumes, cultura, religião, entre outras.

As instituições informais influenciam as formais (verbi gratia, qualquer costume nacional se transforma em lei); por outro lado, instituições formais se relacionam com instituições informais (verbi gratia, uma lei que se transforma em costume). Assim, as instituições formais e informais diferem por diversos motivos: nas instituições formais, ocorrem mudanças em menor espaço de tempo, necessitando da ação coerciva do Estado para serem observadas; as instituições informais, por sua vez, não necessitam de ação coerciva do Estado, pois dependem das crenças do seu povo. As crenças não mudam em espaços de tempos curtos, pelo contrário, demoram muito tempo para se consolidar (ESTEVÃO, 2004).

Partindo da teoria da base de exportação, Schwartzman (1975) explica que o desenvolvimento de uma região depende do dinamismo dessa base e da sua difusão para o resto da economia regional, ou seja, deve apresentar duas condições necessárias para o desenvolvimento: 1) manutenção do dinamismo do produto de exportação; e 2) difusão do dinamismo para outros setores da economica (Figura 1). A primeira condição é ter um crescimento da renda real de uma economia para se ter desenvolvimento econômico. Sendo assim, é necessário que a venda dos produtos de exportação esteja crescendo a uma taxa expresiva para que condições necessárias ao desenvolvimento sejam criadas na região.

Figura 1 - Fatores que condicionam a capacidade de uma região se desenvolver a partir de uma base de exportação

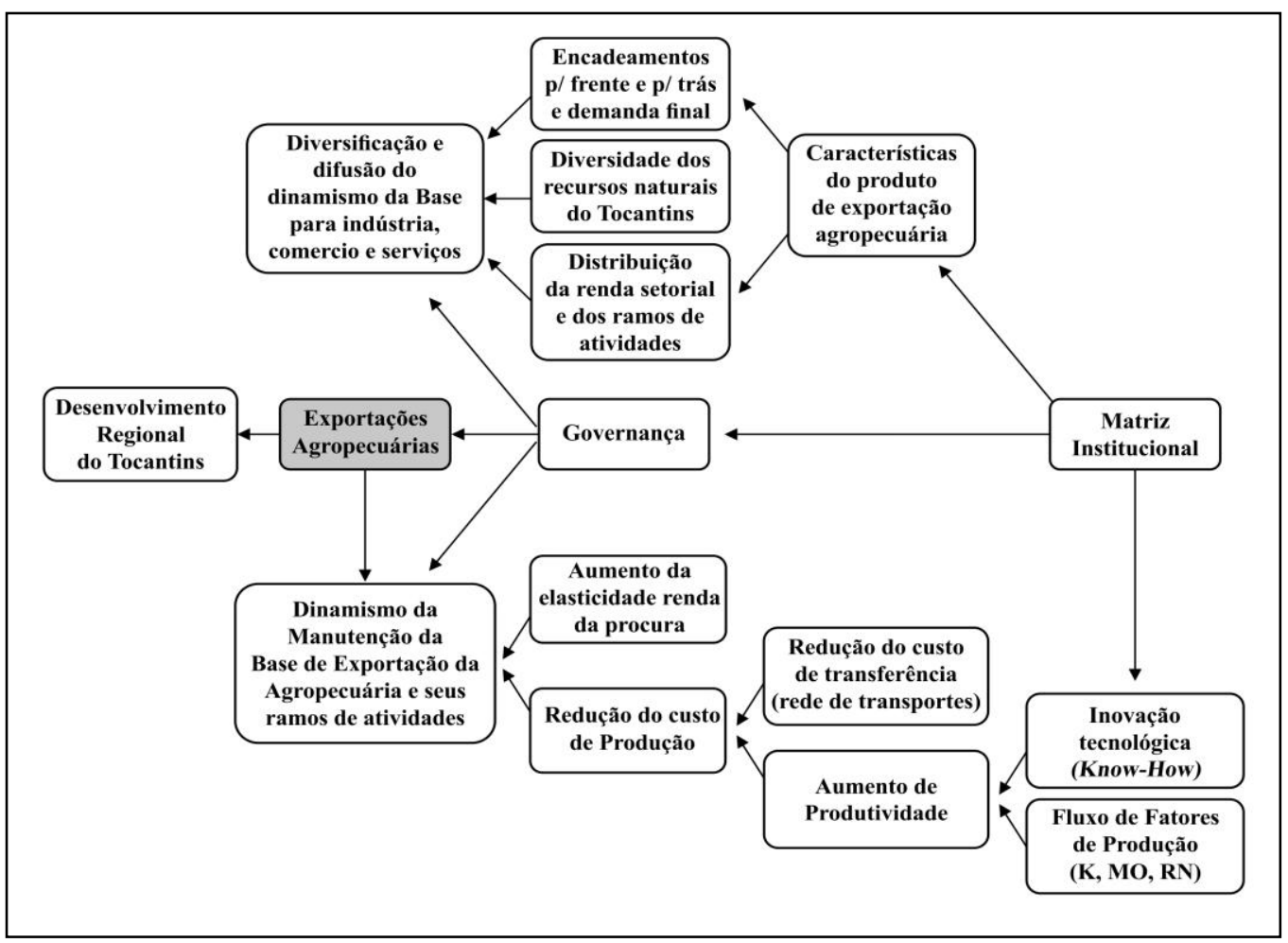

Fonte: Schwartzman (1975), adaptado pelo autor

DRd - Desenvolvimento Regional em debate (ISSNe 2237-9029) v. 6 , n. 3, p. 32-61, nov. 2016. 
Na segunda condição, a difusão ocorre quando o produto de exportação desenvolve outros setores da economia e, para que isso aconteça, é necessário que outras atividades produtivas surjam, que a distribuição de renda atinja um número elevado de pessoas e que surjam outras bases de exportações.

Para manter o dinamismo dos produtos de exportação, dois fatores são importantes: 1) a elasticidade-renda da demanda, que determina a possibilidade de a região manter seu dinamismo por meio de um só produto de exportação, ou seja, tendo o produto uma baixa elasticidade-renda, não haverá tendência para aumento de suas vendas à medida que as regiões importadoras se desenvolvem; 2) custo do produto de exportação, a redução do custo do produto fará com que haja aumento da sua capacidade competitiva, portanto, deve melhorar a rede de transporte e/ou pelo aumento da produtividade através dos fatores de produção.

A atividade total de uma região apresenta uma dicotomia bastante nítida, constando, de um lado, as atividades básicas (exportação) e, do outro, as atividades locais (mercado interno). Na concepção de North (1977b), a região só se desenvolve a partir da sua base exportadora e dos arranjos institucionais para fortalecer essa base. As rendas geradas pela procura externa de bens e de serviços impulsionam as atividades locais e diminuem os custos de transação. Esse conceito de base econômica ou de exportação pode ser empregado para a análise tanto de regiões como de setores ou de ramos de atividades urbanas.

A matriz institucional e a governança, Figura 1, complementam os fatores que condicionam a capacidade de uma região se desenvolver. A matriz institucional, segundo North (1991, 1994), ocupa lugar central na análise do processo de desenvolvimento econômico, porque define o ambiente em que funciona a economia e promove a interação entre as pessoas, e porque a mudança institucional define o modo como a sociedade evolui no tempo. A matriz institucional é formada pelo conjunto de instituições políticas, econômicas e sociais de uma sociedade

O conceito de governaça, segundo Dallabrida (2011), é o exercício do poder e autoridade para gerenciar um país, território ou região, compreendendo mecanismos, processos e instituições por meio das quais os cidadãos e grupos articulam seus interesses públicos, incluindo entre os atores representações dos agentes estatais.

O exercício da governança territorial acontece pela atuação dos diferentes atores, nas instituições, incluindo o Estado, e organizações da sociedade civil, em redes de poder socioterritorial. Redes de poder socioterritorial compreendem a representação de suas lideranças, constituindo a principal estrutura de poder que, em cada momento da história, assume posição hegemônica, tornando-se capaz de dar a direção político-ideológica ao processo de desenvolvimento (DALLABRIDA; BECKER, 2003).

Assim sendo, utiliza-se o termo governança para se referir às iniciativas ou às ações que expressam a capacidade de uma sociedade organizada territorialmente para gerir os assuntos públicos, tendo como referência o envolvimento conjunto e cooperativo dos atores sociais, econômicos e institucionais, incluindo, naturalmente, o Estado com seus diferentes agentes, que, no caso do Brasil, estão presentes nas instâncias municipal, estadual e federal. A governança, assim, é o ato de atribuir poder à sociedade para governar. Portanto, o exercício da governança é feito por meio de relações de poder (DALLABRIDA, 2007). 
Esses fatores condiconam a capacidade de uma região se desenvolver considerando uma base de exportação, juntamente com a matriz institucional e a governça do Brasil e do Estado do Tocantins. Quando bem empregada, as ações poderão influenciar no processo de desenvolvimento regional, atuando efetivamente com políticas públicas do Governo Federal, Estadual e Municipal, incentivando a interação setorial, sua inovação, principalmente com financiamentos e concessão de crédito, além de outras políticas, tais como construção e melhoria da rede de transporte, melhoria dos pequenos corredores estaduais e municipais que ligam ao grande corredor do Estado do Tocantins, a Rodovia Belém-Brasília, a BR-153, telecomunicações, politicas agroindústriais, entre outras.

A base de exportação, a matriz intitucional e a governança podem condicionar a capacidade do Estado do Tocantins a se desenvolver, agregando os pequenos municípios que estão fora do núcleo do centro dimânico de base diversificada.

A seguir, será apresentado o método do Índice de Desenvolvimento Regional (IDR).

\section{MÉTODO DO ÍNDICE DE DESENVOLVIMENTO REGIONAL (IDR)}

O método do Índice de Desenvolvimento Regional (IDR) tem como propósito de identificar e classificar os municípios polo de base econômica ${ }^{5}$, intermediários e retardatários no Estado do Tocantins, proposto por Gualda (1995). Rodrigues (1994) construiu o Índice de Desenvolvimento Social (IDS) para avaliar o grau de desenvolvimento social das grandes regiões brasileiras e dos estados brasileiros. Gualda (2003) empregou o Índice de Desenvolvimento Regional para identificar os municípios que apresentam características de polos de crescimento regional e os efeitos do processo de polarização sobre os demais municípios do Estado do Paraná. Eberhardt e Ferrera de Lima (2012) utilizaram-se desse indicador para analisar o perfil e o estágio do desenvolvimento das Microrregiões do Estado do Paraná, nos anos de 2000 e 2007.

O Índice de Desenvolvimento Regional (IDR), construído com base em indicadores sociais e econômicos, mostra o grau de desenvolvimento em que cada município se encontra. Foi dado maior peso para o indicador econômico, pois o município com melhor situação econômica tem melhores condições para investir em saneamento básico, educação e saúde, sem contar a capacidade de gerar empregos e, assim, melhorar seu indicador social. A estimativa do IDR utiliza as variáveis expostas no Quadro 1.

\footnotetext{
${ }^{5}$ Daqui para frente, os municípios do Tocantins são classificados em Municípios Polos de Base Econômica, Municípios Intermediários de Base Econômica e Municípios Retardatários de Base Econômica.
} 
Quadro 1 - Variáveis utilizadas na estimativa do Índice de Desenvolvimento Regional

\begin{tabular}{|l|l|}
\hline \multicolumn{1}{|c|}{ Indicador Social (IS) } & \multicolumn{1}{c|}{ Indicador Econômico (IE) } \\
\hline População urbana & Produto Interno Bruto (PIB) municipal total (mil reais) \\
\hline População rural & Arrecadação de ICMS \\
\hline Consumo de energia elétrica residencial (Mwh) & Fundo de participação municipal (FPM) \\
\hline Média de anos de estudos & Arrecadação de IPVA \\
\hline Médicos por mil habitantes & Consumo de energia setorial (Mwh) \\
\hline$\%$ de água encanada & Emprego Formal Total \\
\hline$\%$ de coleta de lixo & \multicolumn{1}{|}{-} \\
\hline Leito hospitalar por habitante & - \\
\hline Despesas municipais com saneamento e saúde & - \\
\hline$\%$ de pessoas pobres no município & - \\
\hline Despesas com educação e cultura & \\
\hline
\end{tabular}

Fonte: IBGE (censo populacional); Ipeadata; PNUD; RAIS: Relação Anual de Informações Sociais (2000 e 2010).

Nota: Os valores estão em mil reais, deflacionados pelo deflator implícito do PIB nacional, atualizado em 20/06/2013 pelo Ipeadata.

Os indicadores expostos no Quadro 1 refletem as condições gerais de vida da população. Com a melhora no desempenho dos indicadores econômicos, o Estado ou o município conseguirá mais recursos para investir e melhorar seus indicadores sociais.

Após a escolha, o levantamento e a ordenação dos dados, foi feita a estimativa do Índice de Desenvolvimento Regional (IDR), que serve para classificar o perfil econômico e social de cada município em relação ao estado, nas seguintes etapas:

1) Participação relativa de cada município em relação ao total do Estado;

2) Construção dos índices parciais de cada variável;

3) Construção de indicadores sociais e econômicos; e.

4) Estimação do Índice de Desenvolvimento Regional.

Uma vez determinados os indicadores sociais e econômicos, obteve-se, pela média aritmética ponderada desses elementos, o Índice de Desenvolvimento Regional, atribuindo peso $(0,4)$ para o indicador social e $(0,6)$ para o indicador econômico. O Quadro 2 apresenta os procedimentos da estimativa do Índice de Desenvolvimento Regional (IDR). 
Quadro 2 - Índices e variáveis que compõem o Índice de Desenvolvimento Regional (IDR)

\begin{tabular}{|c|c|}
\hline Índices & Variáveis \\
\hline Part. $=\frac{W_{i}}{W_{V}}$ & $\begin{array}{l}\mathrm{W}_{\mathrm{i}}=\text { valor do município para a variável. } \\
\sum \mathrm{W}_{\mathrm{i}}=\text { valor total do Estado. }\end{array}$ \\
\hline$I P W i=\frac{W_{i}-W_{\min }}{W_{\max }-W_{\min }}$ & $\begin{array}{l}\mathrm{IPW}_{\mathrm{i}}=\text { índice parcial da variável } \mathrm{W} \text { do município } \mathrm{i} \text {; } \\
\mathrm{W}_{\mathrm{i}}=\text { participação da variável } \mathrm{W} \text { do município } \mathrm{i} ; \\
\mathrm{W}_{\min } \text { corresponde à participação do município com o menor } \\
\text { valor; } \\
\mathrm{W}_{\max } \text { corresponde à participação do município com o maior } \\
\text { valor; }\end{array}$ \\
\hline 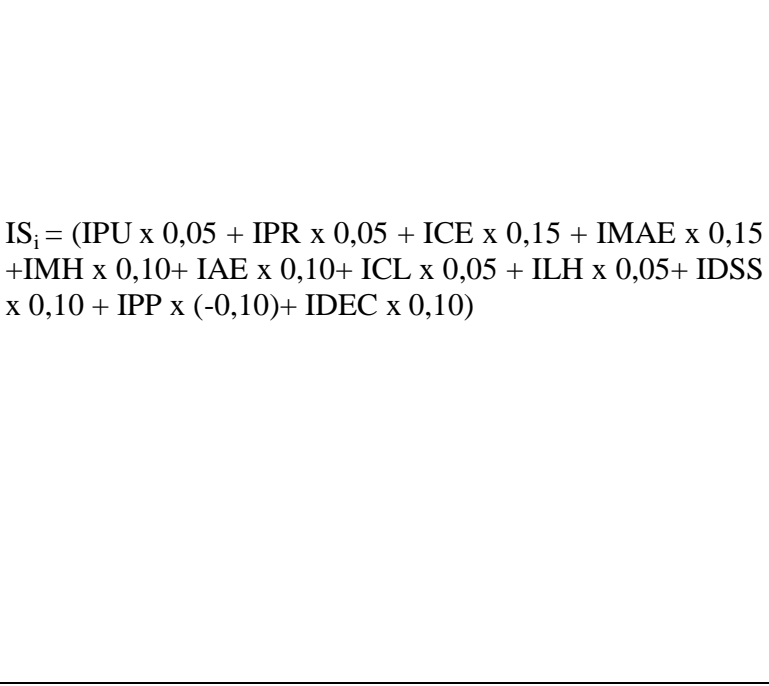 & $\begin{array}{l}\text { IS } S_{\mathrm{i}}=\text { Indicador Social do Município i: } \\
\text { IPU = Índice de participação da população urbana do } \\
\text { município i; } \\
\text { IPR = Índice de participação da população rural do município } \\
\text { i; } \\
\text { ICE = Índice de consumo de energia residencial do município } \\
\text { i; } \\
\text { IMAE = Índice de média de anos de estudo do município i; } \\
\text { IMH = Índice de médicos por mil habitantes do município i; } \\
\text { IAE= Índice das unidades abastecidas com água encanada do } \\
\text { município i; } \\
\text { ICL = Índice de coleta de lixo do município i; } \\
\text { ILH = Índice de leitos hospitalares por habitantes do } \\
\text { município i; } \\
\text { IDSS = Índice de despesas com saneamento e saúde do } \\
\text { município i; } \\
\text { IPP = Índice de pessoas pobres do município i; } \\
\text { IDEC = Índice de despesas com educação e cultura do } \\
\text { município i; }\end{array}$ \\
\hline $\begin{array}{l}\text { IEi }=(\text { IPIB } \times 0,30+\text { ICMS x } 0,15+\text { IFPM x } 0,05+ \\
\text { ICES x } 0,05+\text { IPVA x } 0,05+\text { IE x 0,40) }\end{array}$ & $\begin{array}{l}\mathrm{IE}_{\mathrm{i}}=\text { Indicador Econômico do estado i: } \\
\mathrm{IPIB}=\text { Índice da Participação do Produto Interno Bruto do } \\
\text { município i; } \\
\text { ICMS }_{\mathrm{i}}=\text { Índice da Participação da Arrecadação do ICMS do } \\
\text { município i; } \\
\text { IFPM = Índice do Fundo de participação do município i } \\
\text { ICES = Índice do Consumo de energia elétrica setorial do } \\
\text { município i; } \\
\text { IPVA: Índice de participação do IPVA arrecadado do } \\
\text { município i; } \\
\text { IE }_{\mathrm{i}}=\text { Índice da participação do emprego total do município i; }\end{array}$ \\
\hline
\end{tabular}

Fonte: Adaptado de Gualda (1995).

Uma vez determinado o IDR para cada município, é possível ordená-lo segundo o grau de dinamicidade. Os municípios que apresentaram IDR igual ou superior a 0,1 foram classificados como municípios polo de desenvolvimento regional. Apresentam uma dinâmica na sua base produtiva com potencial de crescimento e de consumo. Os municípios cujo IDR se situa no intervalo compreendido entre 0,099 a 0,050 foram considerados intermediários, ou seja, apresentam uma estrutura econômica e social em crescimento, não obstante sua dinâmica ser inferior à dos municípios polo, pois conseguem atrair recursos e renda dos municípios retardatários. Os municípios com IDR abaixo de 0,050 foram considerados retardatários, sem qualquer capacidade de implementar um processo de crescimento e desenvolvimento econômico, pois não conseguem reter nem atrair recursos de forma a assegurar as condições mínimas de um processo de desenvolvimento regional.

Os critérios de classificação são apresentados no Quadro 3. 
Quadro 3 - Classificação do Índice de Desenvolvimento Regional (IDR)

\begin{tabular}{|c|c|}
\hline Municípios Polo de Base Econômica & IDR de 1,0 a 0,1 \\
\hline Municípios Intermediários de Base Econômica & IDR de 0,099 a 0,050 \\
\hline Municípios Retardatários de Base Econômica & IDR abaixo de 0,050 \\
\hline
\end{tabular}

Fonte: Gualda (1995; 2003), adaptado pelo autor.

Neste artigo, segue-se a classificação de municípios polo como base econômica, pois têm uma centralidade exercida em sua área de influência, seja ela, pelo comércio e pelos serviços ofertados. Nesse sentido, a teoria do lugar central de Christaller (1966) afirma que o desenvolvimento e o crescimento das áreas urbanas dependem do tipo de serviço fornecido ao seu entorno. Com a melhoria dos indicadores econômicos, o município terá recursos para melhorar os indicadores sociais. Com o aumento de produtividade dos trabalhadores, eles tendem a auferir maior renda e despender mais com consumo. Com maior consumo, as firmas tendem a aumentar sua produção de bens e serviços e a empregar uma parcela maior de mão de obra, significando maior receita tributária para o município e Estado, que poderá ampliar seus gastos em melhorias sociais.

A construção do Índice de Desenvolvimento Regional (IDR) foi necessária para a ordenação dos dados e informações referentes aos 139 municípios tocantinenses. Como o objetivo é medir a evolução do processo de desenvolvimento regional e a dinaminicidade dos municípios, os dados foram coletados em 2000 e 2010. A Figura 2 mostra a localização dos 139 municípios do Estado do Tocantins, com sua respectiva numeração, que corresponde a cada município elencado na Tabela 1. 
Figura 2 - Representação da localização dos Municípios do Estado do Tocantins

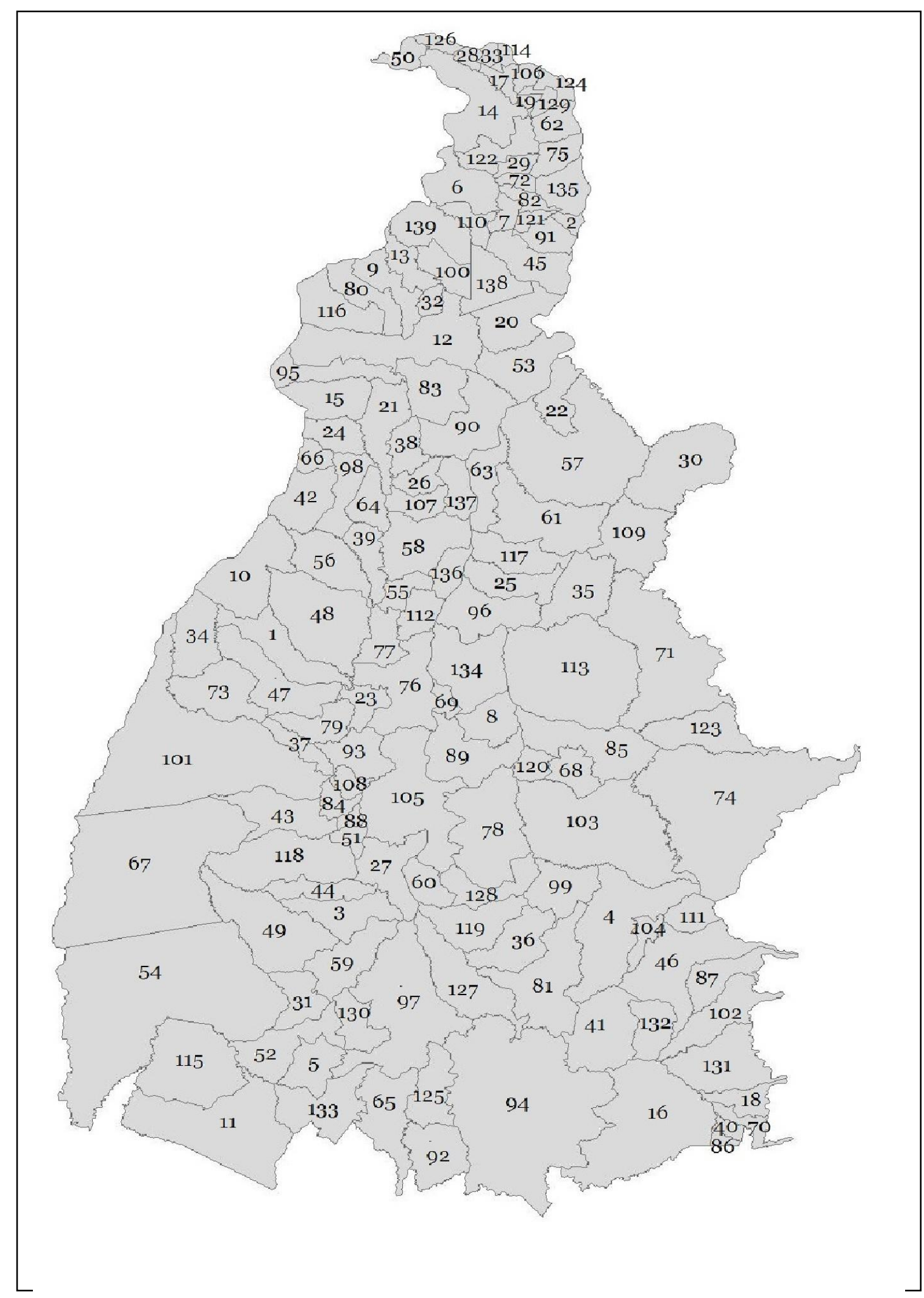

Fonte: IBGE (2010), adaptado pelo autor.

DRd - Desenvolvimento Regional em debate (ISSNe 2237-9029) 
Tabela 1 - Relação dos Municípios do Estado do Tocantins

\begin{tabular}{|c|c|c|c|c|c|}
\hline \multicolumn{6}{|c|}{ Municípios do Estado do Tocantins } \\
\hline 1 & Abreulândia & 48 & Dois Irmãos do Tocantins & 95 & Pau d' Arco \\
\hline 2 & Aguiarnópolis & 49 & Dueré & 96 & Pedro Afonso \\
\hline 3 & Aliança do Tocantins & 50 & Esperantina & 97 & Peixe \\
\hline 4 & Almas & 51 & Fátima & 98 & Pequizeiro \\
\hline 5 & Alvorada & 52 & Figueirópolis & 99 & Pindorama do Tocantins \\
\hline 6 & Ananás & 53 & Filadélfia & 100 & Piraquê \\
\hline 7 & Angico & 54 & Formoso do Araguaia & 101 & Pium \\
\hline 8 & Aparecida do Rio Negro & 55 & Fortaleza do Tabocão & 102 & Ponte Alta do Bom Jesus \\
\hline 9 & Aragominas & 56 & Goianorte & 103 & Ponte Alta do Tocantins \\
\hline 10 & Araguacema & 57 & Goiatins & 104 & Porto Alegre do Tocantins \\
\hline 11 & Araguaçu & 58 & Guaraí & 105 & Porto Nacional \\
\hline 12 & Araguaína & 59 & Gurupi & 106 & Praia Norte \\
\hline 13 & Araguanã & 60 & Ipueiras & 107 & Presidente Kennedy \\
\hline 14 & Araguatins & 61 & Itacajá & 108 & Pugmil \\
\hline 15 & Arapoema & 62 & Itaguatins & 109 & Recursolândia \\
\hline 16 & Arraias & 63 & Itapiratins & 110 & Riachinho \\
\hline 17 & Augustinópolis & 64 & Itaporã do Tocantins & 111 & Rio da Conceição \\
\hline 18 & Aurora do Tocantins & 65 & Jaú do Tocantins & 112 & Rio dos Bois \\
\hline 19 & Axixá do Tocantins & 66 & Juarina & 113 & Rio Sono \\
\hline 20 & Babaçulândia & 67 & Lagoa da Confusão & 114 & Sampaio \\
\hline 21 & Bandeirantes do Tocantins & 68 & Lagoa do Tocantins & 115 & Sandolândia \\
\hline 22 & Barra do Ouro & 69 & Lajeado & 116 & Santa Fé do Araguaia \\
\hline 23 & Barrolândia & 70 & Lavandeira & 117 & Santa Maria do Tocantins \\
\hline 24 & Bernardo Sayão & 71 & Lizarda & 118 & Santa Rita do Tocantins \\
\hline 25 & Bom Jesus do Tocantins & 72 & Luzinópolis & 119 & Santa Rosa do Tocantins \\
\hline 26 & Brasilândia do Tocantins & 73 & Marianópolis do Tocantins & 120 & Santa Tereza do Tocantins \\
\hline 27 & Brejinho de Nazaré & 74 & Mateiros & 121 & Santa Terezinha do Tocantins \\
\hline 28 & Buriti do Tocantins & 75 & Maurilândia do Tocantins & 122 & São Bento do Tocantins \\
\hline 29 & Cachoeirinha & 76 & Miracema do Tocantins & 123 & São Félix do Tocantins \\
\hline 30 & Campos Lindos & 77 & Miranorte & 124 & São Miguel do Tocantins \\
\hline 31 & Cariri do Tocantins & 78 & Monte do Carmo & 125 & São Salvador do Tocantins \\
\hline 32 & Carmolândia & 79 & Monte Santo do Tocantins & 126 & São Sebastião do Tocantins \\
\hline 33 & Carrasco Bonito & 80 & Muricilândia & 127 & São Valério da Natividade \\
\hline 34 & Caseara & 81 & Natividade & 128 & Silvanóplis \\
\hline 35 & Centenário & 82 & Nazaré & 129 & Sítio Novo do Tocantins \\
\hline 36 & Chapada da Natividade & 83 & Nova Olinda & 130 & Sucupira \\
\hline 37 & Chapada de Areia & 84 & Nova Rosanlândia & 131 & Taguatinga \\
\hline 38 & Colinas do Tocantins & 85 & Novo Acordo & 132 & Taipas do Tocantins \\
\hline 39 & Colméia & 86 & Novo Alegre & 133 & Talismã \\
\hline 40 & Combinado & 87 & Novo Jardim & 134 & Tocantínia \\
\hline 41 & Conceição do Tocantins & 88 & Oliveira de Fátima & 135 & Tocantinópolis \\
\hline 42 & Couto de Magalhães & 89 & Palmas & 136 & Tupirama \\
\hline 43 & Cristalândia & 90 & Palmeirante & 137 & Tupirantins \\
\hline 44 & Crixás do Tocantins & 91 & Palmeiras do Tocantins & 138 & Wanderlândia \\
\hline 45 & Darcinópolis & 92 & Palmeirópolis & 139 & Xambioá \\
\hline 46 & Dianópolis & 93 & Paraíso do Tocantins & - & - \\
\hline 47 & Divinópolis do Tocantins & 94 & Paranã & - & - \\
\hline
\end{tabular}

Fonte: Figura 2. 


\section{PERFIL DO DESENVOLVIMENTO REGIONAL DOS MUNICÍPIOS DO ESTADO DO TOCANTINS}

Tendo por referência a construção dos indicadores sociais e econômicos para 2000 e 2010, foi possível analisar a evolução de algumas variáveis que influenciaram no desempenho do desenvolvimento regional nos municípios do Tocantins. Foram constatados aumento da população urbana, redução da taxa de pessoas pobres, aumento com gastos em educação e saúde e aumento de domicílios atendidos com água e esgoto; por outro lado, a variável médico por mil habitantes não está sendo suficiente para atender a demanda dos municípios, tendo ocorrido também redução do número de leitos hospitalares.

As variáveis econômicas que tiveram maior impacto no processo de desenvolvimento regional do Tocantins foram: PIB Municipal agregado (setores da agropecuária, indústria e serviços); aumento de emprego formal; transferência de fundo de participação municipal (FPM), pois o Tocantins ainda tem grande dependência dessa receita; e aumento da arrecadação do ICMS e do IPVA.

Dessa forma, foi possível estimar o Índice de Desenvolvimento Regional (IDR) tendo como base as variáveis sociais e econômicas. O IDR representa o grau de desenvolvimento dos 139 municípios tocantinenses. A Tabela 2 apresenta a distribuição do IDR para os anos de 2000 e 2010. A relação completa está no Apêndice "A".

Em 2000, havia a seguinte distribuição do IDR: 15 municípios classificados como polos de base econômica, 34 intermediários e 90 retardatários. A partir do ano 2000, Palmas, a capital, começa a liderar, constituindo o principal polo regional do estado, com IDR de 0,871, seguida de Araguaína com 0,507 e Gurupi com 0,421. Constatou-se ainda que a maioria dos polos de base econômica se concentra ao longo da Rodovia Belém-Brasília (BR153), conforme ilustra a Figura 3.

O grande entrave ao processo de desenvolvimento regional, em 2000, foram os 90 municípios classificados com retardatários de base econômica, sem qualquer capacidade de impulsionar um processo de crescimento social e econômico sustentável. Esses municípios representavam $65 \%$ do total dos municípios tocantinenses. Entre os 90 considerados retardatários, 15 municípios apresentaram IDRs negativos, muitos deles localizados na região do Bico do Papagaio, Jalapão e região sudeste do estado (Dianópolis). Os seis com os piores indicadores foram: Lagoa do Tocantins (-0,013), Praia Norte $(-0,014)$, Barra do Ouro (0,015), Carrasco Bonito (-0,017), Mateiros (-0,021) e Esperantina (-0,021). Segundo dados do PNUD (2000), esses municípios não conseguiram superar sua taxa de pobreza, que é um entrave ao processo de desenvolvimento social e econômico. 
Tabela 2 - Distribuição dos municípios segundo o Índice de Desenvolvimento Regional (IDR) - 2000 e 2010

\begin{tabular}{l|c|c|c|r}
\hline Índice de Desenvolvimento Regional (IDR) & \multicolumn{2}{|c}{ Número de Municípios } & \multicolumn{2}{|c}{ Participação (\%) } \\
\cline { 2 - 5 } & 2000 & 2010 & 2000 & 2010 \\
\hline De 1,00 a 0,1 - Polos de base econômica & 15 & 16 & 11 & 12 \\
\hline De 0,09 a 0,05 - Intermediários & 34 & 82 & 24 & 59 \\
\hline Abaixo de 0,05 - Retardatários & 90 & 41 & 65 & 29 \\
\hline Total de Municípios & 139 & 139 & 100,00 & 100,00 \\
\hline
\end{tabular}

Fonte: Resultados da pesquisa (2016).

Figura 3 - Distribuição da localização do IDR dos municípios do Tocantins - 2000

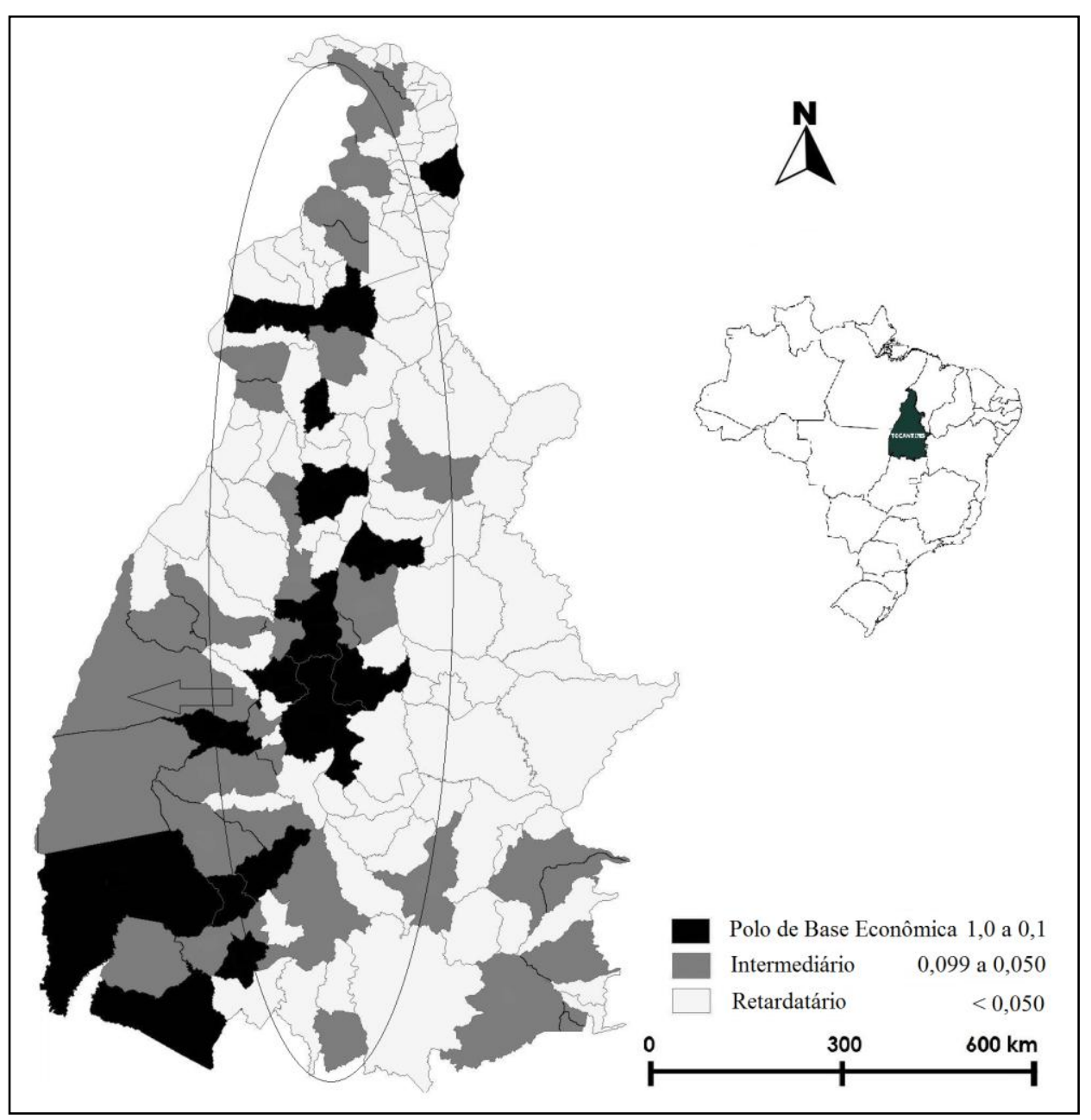

Fonte: adaptado do IBGE (2000).

O município Barra do Ouro tem $74 \%$ das pessoas consideradas pobres, Carrasco Bonito (85\%), Lagoa do Tocantins (80\%), Mateiros (72\%), Esperantina (81\%). Foram consideradas pessoas pobres aquelas que sobrevivem com renda per capita de até meio salário mínimo mensal. Essas taxas não são piores por causa da transferência de renda via Programa do Bolsa Família, pensão, benefícios e aposentaria do meio rural do Governo Federal (PNUD, 2000). 
A partir de 2010, verificou-se melhora sensível do IDR: os municípios polo de base econômica passaram a ser 16; os municípios intermediários passaram de 34 em 2000 para 82 em 2010, correspondendo a 59\% do total do estado. O grande avanço ocorreu nos municípios classificados como retardatários de base econômica, que passaram de 90 em 2000 para 41 municípios em 2010, isto é, 49 municípios passaram a ser considerados intermediários. A participação percentual dos municípios considerados retardatários, que era de $65 \%$ em 2000, caiu para $29 \%$.

Essa melhoria do IDR em 2010 se deveu, sobretudo, ao desempenho social e econômico, consequência da redução da taxa de pessoas pobres e do aumento de empregos nos setores produtivos. O Estado vem a cada ano se consolidando como grande produtor de grãos, sendo a soja a principal cultura, que vem se ampliando em diversos municípios. A região de MATOPIBA, região de interface entre os estados do Maranhão, Tocantins, Piauí e Bahia, foi responsável pela produção de aproximadamente 3,5 milhões de toneladas de grãos, sendo a soja a principal cultura, com 2,22 milhões de toneladas produzidas em 2013/2014 (CONAB, 2014). Considerando o crescimento da área colhida e da produção de grãos de soja, constatou-se considerável elevação na produção e na área plantada no Tocantins.

Os municípios que se destacam na produção de soja são: Campos Lindos, Guaraí, Palmas, Aparecida do Rio Negro, Brejinho de Nazaré, Tupirama, Tupiratins, Porto Nacional, Pedro Afonso, Figueirópolis e Cariri do Tocantins. Os principais municípios a serem contemplados com investimentos indústrias são: Campos Lindos, no norte do estado; Formoso do Araguaia, no sul; e Porto Nacional, na região de Palmas, fundamentalmente no setor de alimentos. Palmas e Miracema do Tocantins devem ser contemplados por investimentos em serviços públicos, especialmente em infraestrutura, que deve, em um futuro próximo, servir de incentivo para a instalação de novas empresas (TOCANTINS, 2014).

A característica das indústrias instaladas no Tocantins são o grande número de unidades de pequeno porte, $86 \%$ do total, e a inexistência de unidades de grande porte, acima de 600 empregados. Para as produtoras de bens de consumo duráveis, o percentual de unidades médias é um pouco maior que para o conjunto da indústria, ocupando mais da metade do total de pessoal desse grupo. No setor de bens intermediários, ao contrário, há uma elevada concentração do pessoal ocupado em unidades de pequeno porte. A indústria extrativa é outro segmento que deve se expandir contando com a expansão de investimentos em transporte, como a Ferrovia Norte-Sul, aproveitando a existência de grande número de jazidas minerais (FIETO, 2010).

A Figura 4 assim como a Figura 3 mostram predominância da concentração dos municípios polo ao longo da rodovia BR-153 (Belém-Brasília). Os municípios polo acabam irradiando o processo de desenvolvimento para os municípios intermediários, e esses, por sua vez, para os retardatários.

Os municípios considerados polo obtiveram mudanças estruturais, em especial na parte econômica, em seguida, na social, tendo passado por diversas transformações, que acabaram por atrair investimentos que proporcionassem um grau de infraestrutura compatível com o crescimento sustentável. Esses municípios se tornaram polo em suas regiões, o que fez com que eles tivessem suas forças centrípetas atuando de forma a atrair mais investimentos e também contingente populacional, vindo de municípios menos desenvolvidos. 
Os municípios considerados de base retardatária não conseguem atrair investimentos e populações, porque estão abaixo de uma base econômica, na linha de sobrevivência. Por outro lado, nos municípios considerados retardatários, foram constatadas migração da população urbana e rural para os municípios mais desenvolvidos, baixa capacidade produtiva e poucas atividades econômicas capazes de gerar empregos, a não ser no setor de serviços e administração pública.

Figura 4 - Distribuição da localização do IDR dos municípios do Tocantins - 2010

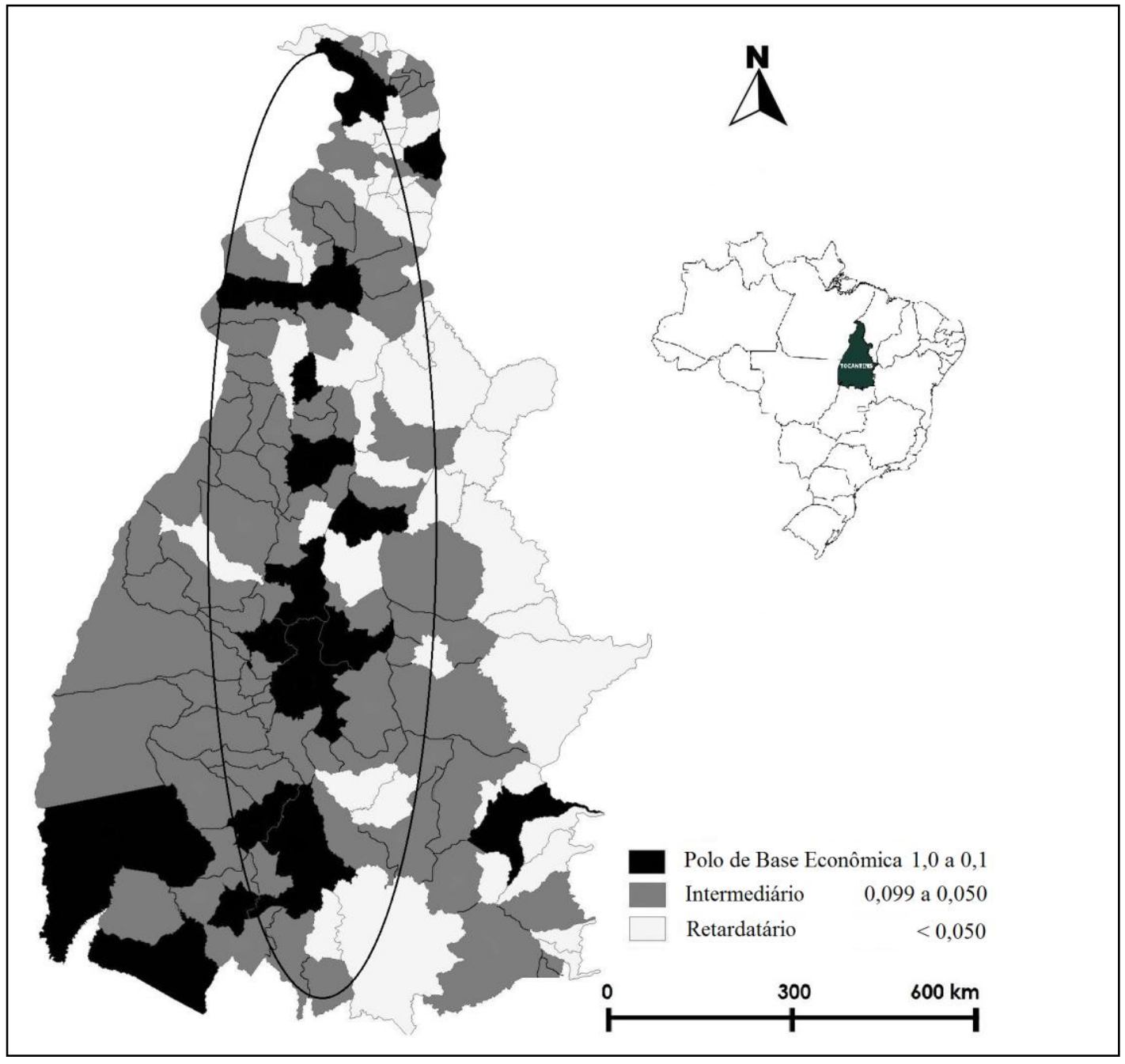

Fonte: adaptado do IBGE (2000).

A Figura 5 mostra a distribuição dos municípios conforme sua classificação - polo, intermediários e retardatários de base econômica - tendo como referência o ano de 2010 . Percebe-se uma sobreposição do ano 2010 sobre o ano de 2000, tendo sido melhoradas a distribuição do IDR e a quantidade de municípios que se sobressaíram em 2010, se comparado ao ano de 2000. Em termos de participação, Tabela 2, em 2000, os municípios polo correspondiam a 11\%; em 2010, este percentual passou para 12\%. Nos municípios intermediários, em 2000, a participação era de apenas $24 \%$, passando para quase $60 \%$ em 2010. O grande avanço foi na redução dos municípios retardatários que, em 2000, representavam 65\% do total, tendo essa percentagem sido reduzida para $29 \%$ em 2010. 
Percebeu-se, durante a análise dos dados, que o impulso da melhora do IDR esteve ligado tanto ao indicador social, transferência de renda do Governo Federal, como também ao indicador econômico, aumento de empregos nos setores produtivos e aumento do Produto Interno Bruto municipal.

Figura 5 - Distribuição dos municípios do Índice de Desenvolvimento Regional (IDR)-2010, conforme sua classificação - municípios polo, intermediários e retardatários

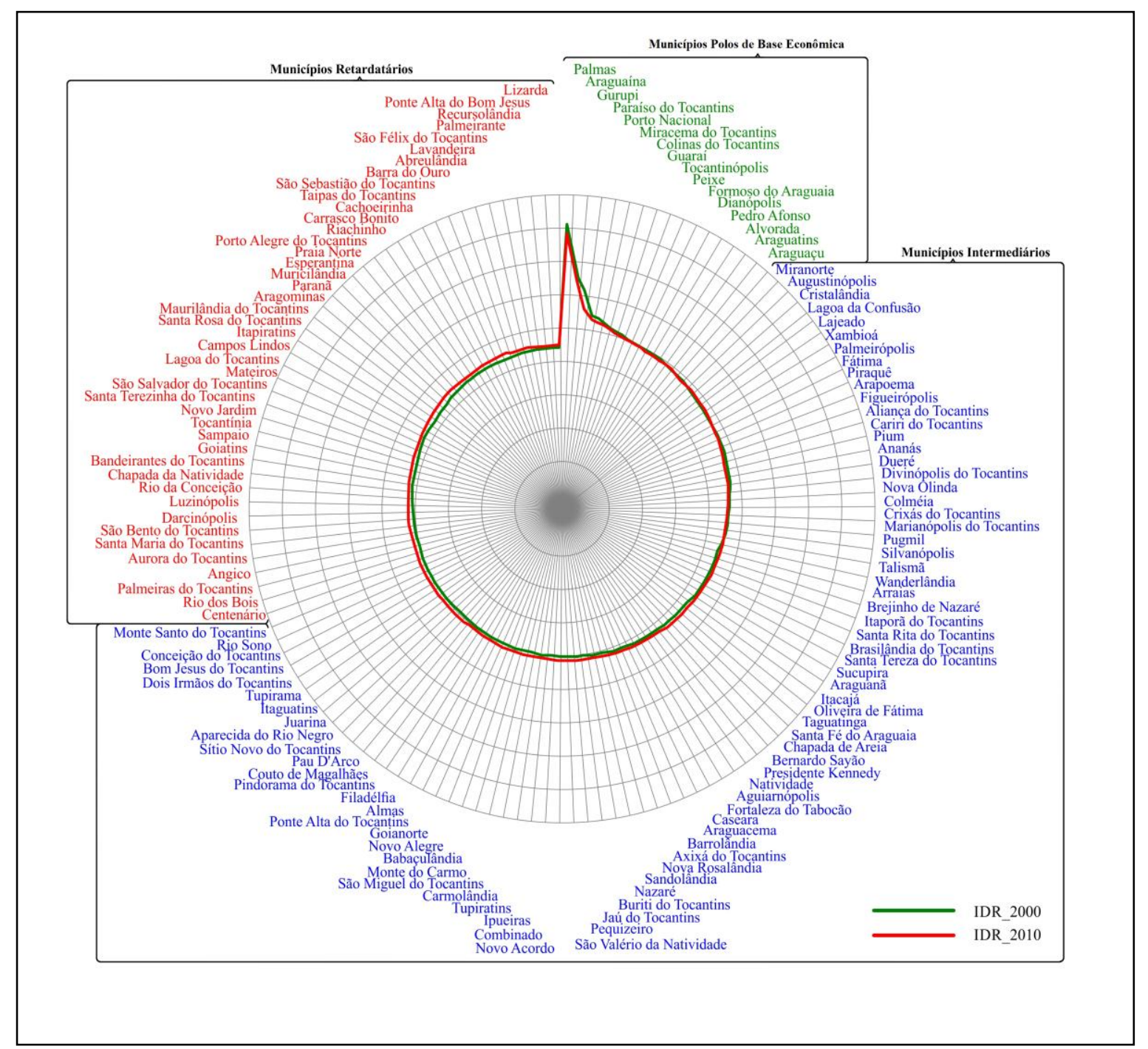

Fonte: Resultado da pesquisa (2016).

Grande parte dos municpios intermediários conseguiu al desempenho por se localizar em área de conurbação do polo e absorver efeitos decorrentes da concentração de aglomeração das atividades produtivas - renda e salários dos trabalhadores - caso dos muncipios localizados na região de Araguaína, Tocantinópolis, Palmas, a capital do estado, e Gurupi, sul do estado. Outros municípos obtiveram tal performace em razão de terem alguma atividade econômica, um comércio varejista forte e agroindústrias que operam no sistema de integração de produção. Constatou-se, ainda, que alguns municípios obtiveram IDR acima de 0,050, que, além do efeito do indicador social, ajudou também no desempenho das atividades agropecuárias, com destaque para a pecuária, o cultivo da soja, milho, cana-de-acúçar e frutas tropicais (melancia, abacaxi e coco). 
O Quadro 4 sintetiza os fatores de influência das atividades base dos setores produtivos que os municípios polo de base econômica exercem sobre os municípios intermediários, com seus respectivos IDR, em 2010.

Quadro 4 - Fator de influência dos municípios polo de base econômica sobre os municípios intermediários em 2010

\begin{tabular}{|c|c|}
\hline $\begin{array}{c}\text { Fator de Influência de Atividade Produtiva } \\
\text { Municípios polo de base econômica }\end{array}$ & Municípios intermediários de base econômica \\
\hline $\begin{array}{l}\text { Extremo norte, na Microrregião do Bico do Papagaio, } \\
\text { destacam-se os municípios de Tocantinópolis }(0,128) \\
\text { e Araguatins }(0,105) \text {. Atividades predominantes: } \\
\text { comércio, administração pública e serviços, que } \\
\text { representam } 72 \% \text { dos empregos gerados. A indústria } \\
\text { teve um crescimento de } 28 \% \text { em } 2010 \text {. Na } \\
\text { Agropecuária, destacam-se a criação de aves e bovino } \\
\text { e o cultivo de mandioca, milho, arroz sequeiro. }\end{array}$ & $\begin{array}{l}\text { Augustinópolis }(0,095) \text {, Aguiarnópolis }(0,095) \text {, } \\
\text { Ananás }(0,081) \text {, Axixá do Tocantins }(0,064) \text {, Buriti do } \\
\text { Tocantins }(0,063) \text {, São Miguel do Tocantins }(0,06) \\
\text { Sitio Novo do Tocantins }(0,055) \text { e Itaguatins }(0,052) \text {. }\end{array}$ \\
\hline $\begin{array}{l}\text { A microrregião de Araguaína compreende Araguaína } \\
(0,479) \text { e Colinas do Tocantins (0147). Setores } \\
\text { predominantes: Agroindústria, criação de aves e } \\
\text { bovinos, indústria de transformação, frigorífico, } \\
\text { construção civil. Araguaína ocupa a segunda posição } \\
\text { do PIB do Tocantins, conhecida como a capital } \\
\text { econômica do estado. A BR-153 exerce forte fator no } \\
\text { crescimento e desenvolvimento. }\end{array}$ & $\begin{array}{l}\text { Xambioá }(0,085) \text {, Arapoema }(0,083) \text {, Nova Olinda } \\
(0,078) \text {, Piraquê }(0,084) \text {, Wanderlândia }(0,072) \text {, } \\
\text { Araguanã }(0,070) \text {, Santa Fé do Araguaia }(0,069) \text {, } \\
\text { Babaçulândia }(0,058) \text {, Carmolândia }(0,060) \text {, Filadélfia } \\
(0,056) \text { e Pau D’Arco }(0,055) \text {. }\end{array}$ \\
\hline $\begin{array}{l}\text { No centro do estado está a maior polarização, } \\
\text { constituída pela Capital, Palmas }(0,942) \text {, Paraíso do } \\
\text { Tocantins }(0,212) \text {, Porto Nacional }(0,196) \text {, Miracema } \\
\text { do Tocantins }(0,172) \text {, Guaraí }(0,137) \text { e Pedro Afonso } \\
(0,114) \text {. A atividade predominante é a prestação de } \\
\text { serviços como saúde, universidades, hospitais, } \\
\text { escolas, comércio varejista e atacadista, agropecuária } \\
\text { (destaque para bovino, soja e milho). }\end{array}$ & $\begin{array}{l}\text { Miranorte }(0,096) \text {, Colmeia }(0,077) \text {, Araguacema } \\
(0,066) \text {, Divinópolis do Tocantins }(0,079) \text {, Marinópolis } \\
\text { do Tocantins }(0,075) \text {, Lajeado }(0,087) \text {, Silvanópolis } \\
(0,073) \text {, Barrolândia }(0,064) \text {, Presidente Kennedy } \\
(0,068) \text {, Fortaleza do Tabocão }(0,067) \text {, Ipueiras } \\
(0,061) \text {. }\end{array}$ \\
\hline $\begin{array}{l}\text { No sul do estado, destacam-se Gurupi }(0,292) \text {, Peixe } \\
(0,126) \text {, Araguçu (0,104), Alvorada }(0,109) \text {. A } \\
\text { principal atividade é a agrícola, liderada pelo } \\
\text { município de Gurupi, comercializando máquinas e } \\
\text { implementos agrícolas, insumos e fertilizantes, } \\
\text { Cultivam-se soja, arroz e milho. Os setores de } \\
\text { serviços, comércio, construção civil e a criação de } \\
\text { bovinos, complementam as atividades. }\end{array}$ & $\begin{array}{l}\text { Figueirópolis }(0,083) \text {, Palmeirópolis }(0,084) \text {, Aliança } \\
\text { do Tocantins }(0,083) \text {, Cariri do Tocantins }(0,082) \text {, } \\
\text { Talismã }(0,073) \text {, Crixás do Tocantins }(0,075) \text {, Brejinho } \\
\text { de Nazaré }(0,072) \text {, Sucupira }(0,70) \text { e Jaú do Tocantins } \\
(0,063) \text {. }\end{array}$ \\
\hline $\begin{array}{l}\text { Na região do Formoso do Araguaia, destaca-se o } \\
\text { município de Formoso do Araguaia }(0,125) \text {, cuja } \\
\text { atividade principal é o cultivo do arroz irrigado e da } \\
\text { soja. }\end{array}$ & $\begin{array}{l}\text { Lagoa da confusão }(0,092) \text {, Cristalândia }(0,093) \text {, Pium } \\
(0,083) \text {, Dueré }(0,080) \text {, Fátima }(0,084), \text { Pugmil } \\
(0,063) \text {, Sandolândia }(0,069) \text {. }\end{array}$ \\
\hline $\begin{array}{l}\text { Na região sudeste, destaca-se o município de } \\
\text { Dianópolis como polo, o único entre os } 20 \text { municípios } \\
\text { que compõem essa microrregião. As principais } \\
\text { atividades econômicas são prestação de serviços, } \\
\text { comércio, construção civil, criação de gado e o cultivo } \\
\text { de soja, milho. }\end{array}$ & $\begin{array}{l}\text { Arraias }(0,072), \text { Taguatinga }(0,069), \text { Natividade } \\
(0,067), \text { Almas }(0,057) \text {, Combinado }(0,61), \text { Novo } \\
\text { Alegre }(0,057) \text {, Pindorama do Tocantins }(0,055) \text {, } \\
\text { Conceição do Tocantins }(0,051) \text {. }\end{array}$ \\
\hline $\begin{array}{l}\text { A região do Jalapão não teve em nenhum período } \\
\text { analisado um município classificado como polo, mas } \\
\text { destacam-se, nessa região, o turismo ecológico, o } \\
\text { artesanato do capim dourado e o cultivo da soja em } \\
\text { Campos Lindos. }\end{array}$ & $\begin{array}{l}\text { Itacajá }(0,069) \text {, Ponte Alta do Tocantins }(0,057) \text {, Rio } \\
\text { Sono }(0,050) .\end{array}$ \\
\hline
\end{tabular}

Fonte: Resultados da pesquisa (2016).

DRd - Desenvolvimento Regional em debate (ISSNe 2237-9029) 
O desenvolvimento de uma agricultura comercial em algumas regiões do Tocantins significou a implantação do sistema de produção intensiva, utilizado principalmente na cultura da soja, milho e arroz. Nos anos 1990, o arroz e o milho eram as principais culturas do Tocantins, respondendo por mais de $80 \%$ da área colhida no estado. A partir do ano 2000, a soja foi assumindo a liderança na produção estadual, provocando mudanças na composição dos produtos agrícolas. A produção de arroz irrigado foi impulsionada pelo Projeto Rio Formoso, em Formoso do Araguaia. Tal projeto abrange os municípios de Cristalândia, Dueré, Formoso do Araguaia, Lagoa da Confusão e Pium, localizados nas regiões centrooeste e sudoeste do estado.

As principais culturas na safra 2010/2011 foram: a soja, com produção de 991.326 t., área de plantio de 354.875 ha; o arroz, com 447.320 t., com área de plantio de 137.946 ha; o milho, com 282.475 t., área plantada 83.229. O estado produz ainda mandioca (337.026 t.), cana-de-açúcar (664.284 t.), melancia (87.224 t.) e abacaxi (41.946 t.). O Tocantins é o quinto maior produtor de arroz do país, ficando atrás do Rio Grande do Sul, Santa Catarina, Mato Grosso e Maranhão (IBGE, 2010). Noventa por cento arroz produzido no Tocantins é exportado para os estados da Região Norte e Nordeste.

A produção agrícola do Tocantins é ainda modesta quando comparada à produção nacional, exceto o arroz, que ocupou a quinta posição em 2010. A soja representa apenas $1,6 \%$ da produção nacional, o milho representa $0,6 \%$ e a cana-de-açúcar representa $0,1 \%$ (IBGE, 2010), muito embora a expansão da fronteira agrícola da commodity soja venha se intensificando no Tocantins, principalmente nas áreas mais férteis e na região do MATOPIBA.

Por outro lado, a criação de gado bovino aparece como a principal atividade agropecuária do estado, sendo principais raças para corte e leite e nelore para corte. Em 2013, o Tocantins atingiu mais de 8,2 milhões de cabeças. As regiões do estado que registraram maior montante de exportação foram Araguaína, por meio da empresa Minerva S/A, e Gurupi, pela Cooperativa dos produtores de Carnes e Derivados - Cooperfrigu.

O crescimento da exportação de carne de 2010 a 2013 foi de $125 \%$, em 2010 foram comercializadas 22,4 mil toneladas e em 2013, 50,3 mil. Em 2010 foram movimentados US\$ 84.915 milhões e em 2013, US\$ 205.697 milhões. Grande parte da exportação de carne do Tocantins tem como destino a Rússia, Venezuela, Egito e Irã (TOCANTINS, 2014).

A indústria da construção civil no Tocantins ganhou expressão com as obras de infraestrutura e edificação da capital. Esse setor, a cada ano, vem aumentando sua participação na geração de empregos, por meio do Programa Aceleração do Crescimento ${ }^{6}$ (PAC), lançado em 2007. O PAC é um programa do governo federal que engloba um conjunto de políticas econômicas, tendo como objetivo acelerar o crescimento econômico no Brasil na área de infraestrutura como saneamento, habitação, transporte, energia e recursos hídricos. O Tocantins é o primeiro estado da região Norte do país a iniciar os trabalhos do PAC, no setor de habitação. Nesse ínterim, foram investidos aproximadamente R \$139 milhões para a construção de cerca de 5,4 mil moradias para Palmas, Bico do Papagaio e região do Jalapão, além de pavimentação urbana (TOCANTINS, 2008).

\footnotetext{
${ }^{6}$ Mariores detalhes sobre as obras do PAC no Tocantins encontram-se disponíveis em: http://dados.gov.br/dataset/obras-do-pac-programa-de-aceleracao-do-crescimento/resource/4c99efa1-20cb41f0-a77e-58e48df81456
}

DRd - Desenvolvimento Regional em debate (ISSNe 2237-9029) 
Outra informação que ratifica a evolução do setor da construção civil no Tocantins foi o estudo realizado pela consultoria Prospecta Inteligência Imobiliária, que apontou Palmas com uma das melhores cidades para se investir em imóveis. Entre as 100 melhores cidades para investimentos imobiliários no país, Palmas ocupa o $40^{\circ}$ lugar. Em comum, as 100 cidades com maior nota têm características como renda per capita alta, população com boa instrução e de vínculo empregatício, empresas e construtoras atuantes na construção civil e déficit imobiliário (YAZBEK, 2015).

A indústria extrativa mineral do Tocantins vem aumentando sua participação no número de empresas e empregos gerados, tendo gerado, em 2000, 363 empregos e, em 2010, 1.004 empregos formais. Os principais produtos desse setor estão relacionados aos insumos para a construção civil, como areia, brita e argila para a produção de cerâmica. De forma geral, quase todos os setores de atividades no Tocantins aumentaram sua participação na economia como um todo no período de 2000 a 2010, refletindo maior urbanização do estado. Porém, há de se mencionar que as atividades estavam concentradas espacial e setorialmente em apenas três cidades: Palmas, Araguaína e Gurupi (BRASIL. MTE, 2014).

Em 2010, a administração pública, comércio e serviço representaram $80 \%$ do total do emprego gerado no Tocantins. Esses setores, juntos, somavam quase $75 \%$ do PIB do estado, constatando a importância que esses setores representam para a economia do estado.

A teoria do lugar central afirma que o desenvolvimento e o crescimento das áreas urbanas dependem do tipo de serviço fornecido ao seu entorno, ou seja, as áreas de mercado de cada aglomeração urbana. Tendo como referência as áreas de influência, estabelece-se a hierarquia das aglomerações no espaço regional, ou seja, quanto maior a centralidade, maior a área de influência e mais aglomerações na "órbita" de um centro (CHRISTALLER, 1966).

A análise do desenvolvimento social e econômico, segundo a concepção da teoria do lugar central e da base econômica, é feita em relação à região central do estado, tendo Palmas como centro regional, formada por aglomerações das atividades produtivas interligando com cidades como Paraíso do Tocantins, Porto Nacional e Miracema do Tocantins, destacando-se, no norte, Araguaína, como polo regional, e no sul, a cidade de Gurupi.

Tendo como base as áreas de influência das atividades produtivas, Quadro 4, estabelece-se a hierarquia das aglomerações no espaço regional do Tocantins. No entanto, os efeitos de retardamento (backwash effects) previstos por Myrdal (1968) ocorrem na maior parte do estado. $\mathrm{O}$ desenvolvimento regional não ocorre em toda parte ao mesmo tempo e de forma homogênea, manifestando-se com intensidade diferente, por exemplo, nas cidades que estão no entorno da BR-153, principalmente aquelas cidades que têm centralidades de diversas atividades aglomerativas, pessoas e negócios na base de polo diversificado.

Nesse sentido, houve crescimento desequilibrado e concentrado em apenas três municípios - Palmas, Araguaína e Gurupi - todavia, está havendo um transbordamento para cidades mais próximas dos polos regionais de base econômica, redução dos municípios considerados retardatários, conforme mostrou o IDR de 2000 para 2010.

Ademais, a parte compreendida pela região do Bico do Papagaio, Jalapão e a região sudeste do Tocantins está excluída desse processo de desenvolvimento. Estas regiões ainda não encontraram força motriz - política, capacidade institucional, governança, mão de obra qualificada - para atrair indústrias tradicionais e não tradicionais, por não conseguirem

DRd - Desenvolvimento Regional em debate (ISSNe 2237-9029) 
aumentar sua participação na geração de valor adicionado, empregos e tributos. Como consequência, ocorre um processo de esvaziamento dessas localidades, marcado pela forte mobilidade dos fatores de produção em direção à região central do estado - Palmas, Porto Nacional, Paraíso do Tocantins e Miracema do Tocantins - para as regiões de Araguaína e Gurupi e demais municípios localizados às margens da rodovia Belém-Brasília.

O processo de esvaziamento de alguns municípios do Tocantins decorreu do crescimento centrado nos municípios polo, agravando o problema de pobreza nessas localidades. Os municípios que apresentaram maiores populações rurais são aqueles de menor dinamicidade e de baixo desenvolvimento social. São incapazes de implementar políticas públicas voltadas à melhoria da qualidade de vida, gerar emprego e renda, estimulando, assim, o fluxo migratório de jovens e adultos. Grande parte da população rural no Tocantins sobrevive de uma economia de subsistência, com pouco valor agregado.

Esse fluxo migratório de jovens e adultos, que irão procurar emprego e renda, vai constituir parte expressiva da mão de obra nos municípios polo. Esse processo favorece os polos regionais de base econômica diversificada ou de manutenção, que conseguem atrair recursos produtivos dos pequenos municípios à sua volta, bem como difundir renda, inviabilizando qualquer esforço de implementar um plano de desenvolvimento integrado e sustentável no Tocantins.

O processo de desenvolvimento regional do Tocantins à moda Hischman (1958) sobre a dinâmica desse desenvolvimento pressupõe um estado de desequilíbrio, movimento e mudança, que faz com que a economia que está em processo de transformação e formação, caso da economia tocantinense, cresça ao longo do tempo. Essa transformação pode ser impulsionada pelo progresso e avanço de um setor ou ramo de atividades em função de sua capacidade de influenciar os outros. Isso pressupõe que o processo de desenvolvimento regional implique desequilíbrios a montante e a jusante.

\section{CONSIDERAÇÕES FINAIS}

O objetivo deste artigo foi identificar e analisar a conjuntura do processo de desenvolvimento social e econômico regional dos municípios tocantinenses para os anos de 2000 e 2010. O método de análise utilizado foi o Índice de Desenvolvimento Regional (IDR), que foi estimado pelo uso de variáveis sociais e econômicas. Tendo como referência essa estimativa, foi possível mensurar as desigualdades entre os municípios do Tocantins, tendo sido estimado o IDR para os 139 municípios do estado, utilizando ao todo 17 variáveis - onze sociais e seis econômicas.

Os resultados apontaram que o desenvolvimento regional no Tocantins não se deu de forma homogênea no tempo e no espaço. O Estado do Tocantins mostrou profundos desequilíbrios sociais e econômicos em quase todos os municípios, com exceção dos municípios de Palmas, Araguaína e Gurupi.

Com os dados quantitativos analisados sobre a realidade social e econômica dos municípios nas décadas de 2000 e 2010, não foi possível identificar todas as causas, ou 
problemas, devido à peculiaridade de cada município, que envolve valores sociais, comportamentos, hábitos e costumes, que estão cristalizados na vivência territorial dessa comunidade.

Em relação à produção e à reprodução de um espaço, o território do Tocantins foi modificado, transformado pelas redes políticas e econômicas que aí se instalaram: vias rodovias federais e estaduais, Ferrovia Norte-Sul, a Hidrovia Araguaia - Tocantins, comércio, serviços, indústrias tradicionais, aeroportos, agroindústrias e redes bancárias. A construção da BR-153 fez os elos com as cidades do seu corredor e com seus corredores menores, destacando as cidades que estão instaladas ao longo dessa rodovia. Isso implicou a expansão, a ocupação de novas fronteiras agrícolas, a reprodução e a ampliação do capital.

Em 2000, a configuração geoeconômica e social compreendia 15 municípios polo de base econômica diversificada, 34 intermediários e 90 retardatários, que foram denominados de base econômica de sobrevivência porque estavam abaixo da base de manutenção. A partir do ano 2000, Palmas, a capital, começou a liderar como o principal polo regional do estado com IDR de 0,871, seguida de Araguaína com 0,507 e Gurupi com 0,421.

A BR-153, construída pela União, gerou um corredor de desenvolvimento econômico no estado do Tocantins, cortando-o longitudinalmente de Norte a Sul. Esse fato vinculou um engate econômico e social ao longo dessa rodovia, que estimulou uma estrutura produtiva diversificada de investimento, negócios e agroindústrias de transformação, beneficiando apenas três municípios: Palmas, Araguaína e Gurupi. Isso implicou, por outro lado, o isolamento de muitos municípios que estão fora desse corredor ou de corredores menores, que são as estradas estaduais, por não conseguirem se inserir nessa matriz de transporte pelo seu abandono, apresentando muita pobreza e miséria, sendo denominadas, consequentemente, de "corredores da miséria".

Constatou-se, nesta pesquisa, que, dos 90 municípios de base retardatária em 2000, 19 têm nomes com alguma designação de santos: São Felix, São Sebastião, Santa Tereza, Ponte Alta do Bom Jesus, Santa Fé do Araguaia, Santa Maria do Tocantins, Santa Rosa do Tocantins, entre outros. Pode-se inferir uma ligação simbólica com a religiosidade no Tocantins, como um povo resignado e temente a Deus. Esses municípios têm elevados índices de pobreza, precariedade em infraestrutura, pouca atividade econômica, e grande parte dos empregos estão ligados ao poder público municipal, sendo que a grande maioria dessa população sobrevive com transferência de renda do governo federal.

A partir de 2010, constatou-se melhora sensível do IDR. Os municípios polo passaram a ser 16; os municípios intermediários, 82; e os retardatários, apenas 41 municípios. A constatação da melhora do IDR em 2010 se deve, sobretudo, à melhoria do indicador social, como, por exemplo, queda da taxa de pobreza, aumento dos gastos em saúde, em saneamento e em educação. Em relação aos indicadores econômicos, um dos principais fatores foi a criação de novos postos de trabalhos na área de serviços, de comércios e de administração pública. Verificou-se, também, aumento do PIB municipal.

Diante dessa situação aqui retratada, faz-se necessário trilhar alguns caminhos, algumas alternativas na promoção de um desenvolvimento regional mais equitativo para a população do Tocantins, sendo necessárias algumas ações em conjunto.

DRd - Desenvolvimento Regional em debate (ISSNe 2237-9029) 
Os municípios classificados como retardatários necessitam, urgentemente, buscar mecanismos para promover o desenvolvimento local. É necessário construir com toda a sociedade um conjunto de estratégias, identificando suas potencialidades e fragilidades para a saída dessa situação. Para tanto, faz-se necessário buscar apoio junto ao governo estadual e municipal; construir planos estratégicos de médio e longo prazos que possam consolidar o comércio varejista local; promover o turismo na região do Jalapão, onde foram constatados os piores indicadores; divulgar e ampliar o artesanato do "Capim Dourado"; melhorar a eficiência e efetividade dos gastos públicos; e fortalecer o consórcio na área da saúde, educação e, principalmente, a economia solidária. Essas ações, a médio e longo prazos, podem se traduzir em melhor qualidade de vida para a população.

Para futuras pesquisas, sugere-se incluir outros indicadores como o ambiental, institucional e cultural e ampliar as variáveis na construção do Índice de Desenvolvimento Regional (IDR), tanto para o estado do Tocantins quanto para os demais estados da federação.

\section{REFERÊNCIAS}

AREND, M.; CÁRIO, S. A. F. Origens e determinantes dos desequilíbrios no Rio Grande do Sul: uma análise a partir da teoria institucional de Douglass North. Ensaios FEE, Porto Alegre, v. 26, p. 63-94, maio, 2005.

BARBOSA, Y. M. As políticas territoriais e a criação do Estado do Tocantins. 1998. 180f. Tese (Doutorado em Geografia Humana) - Faculdade de Filosofia, Letras, Ciências Humanas, Universidade de São Paulo, São Paulo, 1998.

BOURDIEU, P. O poder simbólico. Lisboa: Difel; Rio de Janeiro: Bertrand Brasil, 1989.

BRASIL. MTE (MINISTÉRIO DO TRABLAHO E EMPREGO). Relação anual de informações sociais (Rais). Anos: 2000, 2010 e 2013. Disponível em:

<http://portal.mte.gov.br/rais/>. Acesso em: 18 ago. 2014.

CÁRDENAS, E.; OJEDA, J. La nueva economía institucional y la teoría de la implementación. Revista de economia institucional, v. 4, n. 6, 2002.

CHRISTALLER, Walter. Central Places in Southern Germany. New Jersy: Prentice-Hall, 1966.

COASE, R. The nature of the firm. Economica, New Series, v. 4, n. 16, p. 386-405, nov. 1937. Disponível em: <http://www.colorado.edu/ibs/eb/alston/ econ4504/readings/ The\%20Nature\%20of\%20the\%20Firm\%20by\%20Coase.pdf >. Acesso em: 20 jan. 2014.

CONAB (COMPANHIA NACIONAL DE ABASTECIMENTO). Levantamentos de safras, 2013/2014. Disponível em: < http://www.conab.gov.br/conteudos.php?a=1253\&t=/>. Acesso em: 18 mai. 2015. 
DALLABRIDA, V. R.; BECKER, D. F. Governança Territorial Um primeiro passo na construção de uma proposta teórico-metodológica. Desenvolvimento em Questão, Ijuí, a. 1, n. 2, p. 73-98, jul./dez./2003,

. A gestão territorial através do diálogo e da participação. In: Scripta Nova. Revista Electrónica de Geografía y Ciencias Sociales. Barcelona: Universidad de Barcelona, v. 11, n. 245, 2007.

(Org.). Governança territorial e desenvolvimento: descentralização políticoadministrativa, estruturas subnacionais de gestão do desenvolvimento e capacidades estatais. Rio de Janeiro: Editora Garamond, 2011.

EBERHARDT, P. H. C.; FERERRA DE LIMA, J. Evolução e estágio do desenvolvimento econômico regional: o caso das regiões do Paraná. Desenvolvimento Regional em Debate, v. 2. n. 1, p. 189-203, jul./dez. 2012.

ESTÊVÃO, J. Desenvolvimento econômico e mudança institucional: o papel do Estado. In: Conferência Internacional Economic Policies in the New Millennium, 2004, Coimbra.

Anais... Coimbra, Portugal: FEUC, abr. 2004.

FIETO (FEDERAÇÃO DAS INDÚSTRIAS DO ESTADO DO TOCANTINS). Incentivos Fiscais do Tocantins 2010. Palmas: FIETO, 2010. Disponível em:

<http://www.fieto.com.br/>. Acesso em: 27 abr. 2015.

GUALDA, N. L. IDR: Proposta Metodológica. Maringá. Texto para Discussão no 15. Programa de Mestrado em Economia. Universidade Estadual de Maringá, 1995.

O Índice de Desenvolvimento Regional como fator de identificação de polos de crescimento regionais - uma tentativa de identificação para a economia paranaense. In: II Encontro de Economia Paranaense, 2003, Maringá. Anais... Maringá: TAC - Multimídia, p. 566-583,2003.

HAESBAERT, R. Des-territorialização e identidade: a rede "gaúcha" no Nordeste. Niterói: EDUFF, 1997

Territórios alternativos, 2.ed, 2. Impr. São Paulo: Contexto, 2009.

HIRSCHMAN, A. O. Interregional and International transmission of economic growth. In: The strategy of economic development. Tradução Rui Cesar dos Santos. New Haven, Yala University Press, 1958, p. 183-201.

IBGE (INSTITUTO BRASILEIRO DE GEOGRAFIA E ESTATÍSTICA). Censos demográficos, econômicos e agropecuários. Anos: 2000 e 2010. Biblioteca digital. Rio de Janeiro. Disponível em:<www.ibge.gov.br.>. Acesso em: 20 fev. 2014.

Contas Regionais do Brasil. 2011, 2012. Disponível em

<http://www.ibge.gov.br/home/>. Acesso em: 25 abr. 2014.

IPEA (INSTITUTO DE PESQUISA ECONÔMICA). Produto interno bruto municipal 2000 e 2010. Disponível em: <http://www.ipeadata.gov.br/>. Acesso em: 20 mar. 2014. 
MORAES, A. C. R. Território e história no Brasil, 2. ed. São Paulo: Annablume, 2005.

MYRDAL, G. Teoria econômica e regiões subdesenvolvidas. 2. ed. Rio de Janeiro: Saga, 1968.

NORTH, D. A agricultura no crescimento econômico. In: SCHWARTZMAN, J. (Org.). Economia regional: textos escolhidos. Belo Horizonte, MG: CEDEPLAR/CETEDRE MINTER, 1977a. p. 333-343

Teoria da localização e crescimento regional. In: SCHWARTZMAN, J. (Org.). Economia regional: textos escolhidos. Belo Horizonte, MG: CEDEPLAR/CETEDRE MINTER, , 1977b. p. 291-314

. Instituions, institutional change ande economic performance. Cambridge: University Press, 1990.

Institutions. Journal of Economic Perspectives. v. 5. n. 1. p. 97-112, 1991.

Desempeño económico en el transcurso de los años. Estocolmo: [s.n.], 1993.

Disponível em: <http://www.eumed.net/cursecon/textos/north-nobel.htm>. Acesso em: 22 jun. 2014.

Liberal, 1994.

Custos de transação, instituições e desempenho econômico. São Paulo: Instituto

PNUD (Programa das Nações Unidas para o Desenvolvimento). Relatório do

Desenvolvimento Humano (RDH), 2000, 2010. Disponível em:

<http://hdrstats.undp.org/en/indicators/103106.html>. Acesso em: 27 jan. 2015.

PUTNAM, R. Comunidade e democracia: a experiência da Itália moderna. Rio de Janeiro: FGV, 2007.

RAFFESTIN, C. Por uma geografia do poder. Tradução de Maria Cecília França. São Paulo: Ática, 1993.

RICHARDSON, H. Economia regional: teoria da localização, estrutura urbana e crescimento regional. Rio de Janeiro: Zahar, 1975.

RODRIGUES, M. O desenvolvimento social nos estados brasileiros. Conjuntura Econômica, Rio de Janeiro, FGV, v. 48, n. 3, p. 54-69, 1994.

SAQUET, M. A. Os tempos e os territórios da colonização italiana. Porto Alegre: ESR Edições, 2003.

SCHWARTZMAN, J. A teoria da base de exportação e o desenvolvimento regional. In: HADDAD, Paulo R. Desequilíbrios regionais e descentralização industrial. Rio de Janeiro: IPEA/INPES, 1975.

SPOSITO, E. S. Contribuição à metodologia de ensino do pensamento geográfico. Presidente Prudente: FCT/UNESP, 2000 (Tese de Livre Docência). 
Sobre o conceito de território: um exercício metodológico para a leitura da formação territorial do sudoeste do Paraná. In: RIBAS, A. D.; SPOSITO, E. S.; SAQUET, M. A. (Org.) Território e desenvolvimento: diferentes abordagens, Francisco Beltrão: Unioeste, 2004, p. $15-36$.

TOCANTINS. Secretaria de Comunicação- SECON. Exportação de carne bovina 2014. Disponível em: <http://secom.to.gov.br/noticia/190988/>. Acesso em: 04 maio 2015.

Secretaria de Planejamento - SEPLAN. Indicadores sociais e econômicos, 2010. Disponível em: <http://seplan.to.gov.br/>. Acesso em: 04 maio 2015.

VEBLEN, T. A teoria da classe ociosa. 3 ed. São Paulo: Nova Cultural. (Os Economistas), 1988.

YAZBEK, P. As 100 melhores cidades do Brasil para investir em imóveis. Revista Exame, São Paulo, 06 de fev. de 2015. Disponível em: <http://exame.abril.com.br/seudinheiro/noticias/as-100-melhores-cidades-do-brasil-para-investir-em-imoveis >. Acesso em: 27 abr. 2015. 


\section{APÊNDICE A - Elaboração do Índice de Desenvolvimento Regional (IDR) dos 139 municípios do Tocantins: 2000 e 2010}

\begin{tabular}{|c|c|c|c|c|}
\hline Municípios & 2000 & Classificação & Municípios & 2010 \\
\hline Palmas & 0,871 & $1^{\circ}$ & Palmas & 0,942 \\
\hline Araguaína & 0,507 & $2^{\circ}$ & Araguaína & 0,479 \\
\hline Gurupi & 0,421 & $3^{\circ}$ & Gurupi & 0,292 \\
\hline Paraíso do Tocantins & 0,242 & $4^{\circ}$ & Paraíso do Tocantins & 0,212 \\
\hline Porto Nacional & 0,223 & $5^{\circ}$ & Porto Nacional & 0,196 \\
\hline Miracema do Tocantins & 0,186 & $6^{\circ}$ & Miracema do Tocantins & 0,172 \\
\hline Formoso do Araguaia & 0,156 & $7^{\circ}$ & Colinas do Tocantins & 0,147 \\
\hline Colinas do Tocantins & 0,152 & $8^{\circ}$ & Guaraí & 0,137 \\
\hline Guaraí & 0,135 & $9^{\circ}$ & Tocantinópolis & 0,128 \\
\hline Cariri do Tocantins & 0,116 & $10^{\circ}$ & Peixe & 0,126 \\
\hline Pedro Afonso & 0,113 & $11^{\circ}$ & Formoso do Araguaia & 0,125 \\
\hline Alvorada & 0,106 & $12^{\circ}$ & Dianópolis & 0,116 \\
\hline Tocantinópolis & 0,104 & $13^{\circ}$ & Pedro Afonso & 0,114 \\
\hline Araguaçu & 0,102 & $14^{\circ}$ & Alvorada & 0,109 \\
\hline Cristalândia & 0,101 & $15^{\circ}$ & Araguatins & 0,105 \\
\hline Dianópolis & 0,097 & $16^{\circ}$ & Araguaçu & 0,104 \\
\hline Figueirópolis & 0,088 & $17^{\circ}$ & Miranorte & 0,096 \\
\hline Palmeirópolis & 0,087 & $18^{\circ}$ & Augustinópolis & 0,095 \\
\hline Arapoema & 0,082 & $19^{\circ}$ & Cristalândia & 0,093 \\
\hline Miranorte & 0,080 & $20^{\circ}$ & Lagoa da Confusão & 0,092 \\
\hline Araguatins & 0,080 & $21^{\circ}$ & Lajeado & 0,087 \\
\hline Taguatinga & 0,075 & $22^{\circ}$ & Xambioá & 0,085 \\
\hline Xambioá & 0,074 & $23^{\circ}$ & Palmeirópolis & 0,084 \\
\hline Dueré & 0,070 & $24^{\circ}$ & Fátima & 0,084 \\
\hline Sandolândia & 0,070 & $25^{\circ}$ & Piraquê & 0,084 \\
\hline Novo Jardim & 0,070 & $26^{\circ}$ & Arapoema & 0,083 \\
\hline Lagoa da Confusão & 0,070 & $27^{\circ}$ & Figueirópolis & 0,083 \\
\hline Aliança do Tocantins & 0,070 & $28^{\circ}$ & Aliança do Tocantins & 0,083 \\
\hline Pium & 0,067 & $29^{\circ}$ & Cariri do Tocantins & 0,082 \\
\hline Barrolândia & 0,066 & $30^{\circ}$ & Pium & 0,082 \\
\hline Fátima & 0,064 & $31^{\circ}$ & Ananás & 0,081 \\
\hline Colméia & 0,063 & $32^{\circ}$ & Dueré & 0,080 \\
\hline Natividade & 0,063 & $33^{\circ}$ & Divinópolis do Tocantins & 0,079 \\
\hline Bernardo Sayão & 0,062 & $34^{\circ}$ & Nova Olinda & 0,078 \\
\hline Piraquê & 0,062 & $35^{\circ}$ & Colméia & 0,077 \\
\hline Augustinópolis & 0,061 & $36^{\circ}$ & Crixás do Tocantins & 0,075 \\
\hline Arraias & 0,061 & $37^{\circ}$ & Marianópolis do Tocantins & 0,075 \\
\hline Combinado & 0,060 & $38^{\circ}$ & Pugmil & 0,074 \\
\hline Itacajá & 0,060 & $39^{\circ}$ & Silvanópolis & 0,073 \\
\hline Peixe & 0,059 & $40^{\circ}$ & Talismã & 0,073 \\
\hline Santa Rita do Tocantins & 0,058 & $41^{\circ}$ & Wanderlândia & 0,072 \\
\hline Ananás & 0,057 & $42^{\circ}$ & Arraias & 0,072 \\
\hline Lajeado & 0,056 & $43^{\circ}$ & Brejinho de Nazaré & 0,072 \\
\hline Tocantínia & 0,056 & $44^{\circ}$ & Itaporã do Tocantins & 0,071 \\
\hline Nova Rosalândia & 0,054 & $45^{\circ}$ & Santa Rita do Tocantins & 0,071 \\
\hline Marianópolis do Tocantins & 0,053 & $46^{\circ}$ & Brasilândia do Tocantins & 0,070 \\
\hline Divinópolis do Tocantins & 0,051 & $47^{\circ}$ & Santa Tereza do Tocantins & 0,070 \\
\hline Novo Alegre & 0,051 & $48^{\circ}$ & Sucupira & 0,070 \\
\hline Nova Olinda & 0,051 & $49^{\circ}$ & Araguanã & 0,070 \\
\hline Ponte Alta do Tocantins & 0,049 & $50^{\circ}$ & Itacajá & 0,069 \\
\hline Brasilândia do Tocantins & 0,045 & $51^{\circ}$ & Oliveira de Fátima & 0,069 \\
\hline Araguacema & 0,045 & $52^{\circ}$ & Taguatinga & 0,069 \\
\hline Talismã & 0,044 & $53^{\circ}$ & Santa Fé do Araguaia & 0,069 \\
\hline
\end{tabular}

DRd - Desenvolvimento Regional em debate (ISSNe 2237-9029)

v. 6, n. 3, p. 32-61, nov. 2016. 


\begin{tabular}{|c|c|c|c|c|}
\hline Municípios & 2000 & Classificação & \begin{tabular}{|r|} 
Municípios \\
\end{tabular} & 2010 \\
\hline Crixás do Tocantins & 0,043 & $54^{\circ}$ & Chapada de Areia & 0,068 \\
\hline Pindorama do Tocantins & 0,043 & $55^{\circ}$ & Bernardo Sayão & 0,068 \\
\hline Brejinho de Nazaré & 0,043 & $56^{\circ}$ & Presidente Kennedy & 0,068 \\
\hline Jaú do Tocantins & 0,043 & $57^{\circ}$ & Natividade & 0,067 \\
\hline Wanderlândia & 0,043 & $58^{\circ}$ & Aguiarnópolis & 0,067 \\
\hline Presidente Kennedy & 0,042 & $59^{\circ}$ & Fortaleza do Tabocão & 0,067 \\
\hline Itaporã do Tocantins & 0,042 & $60^{\circ}$ & Caseara & 0,066 \\
\hline Fortaleza do Tabocão & 0,041 & $61^{\circ}$ & Araguacema & 0,066 \\
\hline Dois Irmãos do Tocantins & 0,039 & $62^{\circ}$ & Barrolândia & 0,064 \\
\hline Oliveira de Fátima & 0,039 & $63^{\circ}$ & Axixá do Tocantins & 0,064 \\
\hline Santa Fé do Araguaia & 0,038 & $64^{\circ}$ & Nova Rosalândia & 0,064 \\
\hline São Valério da Natividade & 0,037 & $65^{\circ}$ & Sandolândia & 0,063 \\
\hline Aurora do Tocantins & 0,036 & $66^{\circ}$ & Nazaré & 0,063 \\
\hline Pequizeiro & 0,036 & $67^{\circ}$ & Buriti do Tocantins & 0,063 \\
\hline Filadélfia & 0,035 & $68^{\circ}$ & Jaú do Tocantins & 0,063 \\
\hline Rio dos Bois & 0,035 & $69^{\circ}$ & Pequizeiro & 0,062 \\
\hline Nazaré & 0,035 & $70^{\circ}$ & São Valério da Natividade & 0,062 \\
\hline Bandeirantes do Tocantins & 0,034 & $71^{\circ}$ & Novo Acordo & 0,062 \\
\hline Carmolândia & 0,033 & $72^{\circ}$ & Combinado & 0,061 \\
\hline Silvanópolis & 0,033 & $73^{\circ}$ & Ipueiras & 0,061 \\
\hline Monte do Carmo & 0,033 & $74^{\circ}$ & Tupiratins & 0,060 \\
\hline Almas & 0,033 & $75^{\circ}$ & Carmolândia & 0,060 \\
\hline Pugmil & 0,032 & $76^{\circ}$ & São Miguel do Tocantins & 0,060 \\
\hline Chapada de Areia & 0,030 & $77^{\circ}$ & Monte do Carmo & 0,059 \\
\hline Aparecida do Rio Negro & 0,030 & $78^{\circ}$ & Babaçulândia & 0,058 \\
\hline Abreulândia & 0,029 & $79^{\circ}$ & Novo Alegre & 0,057 \\
\hline Aguiarnópolis & 0,029 & $80^{\circ}$ & Goianorte & 0,057 \\
\hline Rio da Conceição & 0,028 & $81^{\circ}$ & Ponte Alta do Tocantins & 0,057 \\
\hline Monte Santo do Tocantins & 0,028 & $82^{\circ}$ & Almas & 0,057 \\
\hline Conceição do Tocantins & 0,027 & $83^{\circ}$ & Filadélfia & 0,056 \\
\hline Sucupira & 0,027 & $84^{\circ}$ & Pindorama do Tocantins & 0,055 \\
\hline Caseara & 0,026 & $85^{\circ}$ & Couto de Magalhães & 0,055 \\
\hline Novo Acordo & 0,026 & $86^{\circ}$ & Pau D'Arco & 0,055 \\
\hline Aragominas & 0,025 & $87^{\circ}$ & Sítio Novo do Tocantins & 0,055 \\
\hline Babaçulândia & 0,025 & $88^{\circ}$ & Aparecida do Rio Negro & 0,054 \\
\hline Couto de Magalhães & 0,022 & $89^{\circ}$ & Juarina & 0,053 \\
\hline Paranã & 0,021 & $90^{\circ}$ & Itaguatins & 0,052 \\
\hline Araguanã & 0,020 & $91^{\circ}$ & Tupirama & 0,052 \\
\hline Axixá do Tocantins & 0,019 & $92^{\circ}$ & Dois Irmãos do Tocantins & 0,052 \\
\hline Pau D'Arco & 0,019 & $93^{\circ}$ & Bom Jesus do Tocantins & 0,052 \\
\hline Goianorte & 0,017 & $94^{\circ}$ & Conceição do Tocantins & 0,051 \\
\hline Darcinópolis & 0,017 & $95^{\circ}$ & Rio Sono & 0,050 \\
\hline Rio Sono & 0,016 & $96^{\circ}$ & Monte Santo do Tocantins & 0,050 \\
\hline Taipas do Tocantins & 0,016 & $97^{\circ}$ & Centenário & 0,050 \\
\hline Chapada da Natividade & 0,015 & $98^{\circ}$ & Rio dos Bois & 0,050 \\
\hline Itaguatins & 0,015 & $99^{\circ}$ & Palmeiras do Tocantins & 0,049 \\
\hline Porto Alegre do Tocantins & 0,014 & $100^{\circ}$ & Angico & 0,049 \\
\hline Goiatins & 0,014 & $101^{\circ}$ & Aurora do Tocantins & 0,049 \\
\hline Luzinópolis & 0,013 & $102^{\circ}$ & Santa Maria do Tocantins & 0,048 \\
\hline Angico & 0,013 & $103^{\circ}$ & São Bento do Tocantins & 0,047 \\
\hline Ponte Alta do Bom Jesus & 0,012 & $104^{\circ}$ & Darcinópolis & 0,045 \\
\hline Ipueiras & 0,012 & $105^{\circ}$ & Luzinópolis & 0,045 \\
\hline Buriti do Tocantins & 0,011 & $106^{\circ}$ & Rio da Conceição & 0,045 \\
\hline Sítio Novo do Tocantins & 0,011 & $107^{\circ}$ & Chapada da Natividade & 0,045 \\
\hline Lavandeira & 0,010 & $108^{\circ}$ & Bandeirantes do Tocantins & 0,043 \\
\hline Bom Jesus do Tocantins & 0,010 & $109^{\circ}$ & Goiatins & 0,043 \\
\hline
\end{tabular}

DRd - Desenvolvimento Regional em debate (ISSNe 2237-9029)

v. 6, n. 3, p. 32-61, nov. 2016. 


\begin{tabular}{|c|c|c|c|c|}
\hline Municípios & 2000 & Classificação & Municípios & 2010 \\
\hline Centenário & 0,009 & $110^{\circ}$ & Sampaio & 0,042 \\
\hline Santa Tereza do Tocantins & 0,009 & $111^{\circ}$ & Tocantínia & 0,042 \\
\hline Santa Rosa do Tocantins & 0,008 & $112^{\circ}$ & Novo Jardim & 0,042 \\
\hline São Sebastião do Tocantins & 0,007 & $113^{\circ}$ & Santa Terezinha do Tocantins & 0,041 \\
\hline São Miguel do Tocantins & 0,006 & $114^{\circ}$ & São Salvador do Tocantins & 0,040 \\
\hline Lizarda & 0,005 & $115^{\circ}$ & Mateiros & 0,040 \\
\hline Tupiratins & 0,005 & $116^{\circ}$ & Lagoa do Tocantins & 0,040 \\
\hline Tupirama & 0,005 & $117^{\circ}$ & Campos Lindos & 0,040 \\
\hline São Félix do Tocantins & 0,005 & $118^{\circ}$ & Itapiratins & 0,039 \\
\hline Palmeiras do Tocantins & 0,003 & $119^{\circ}$ & Santa Rosa do Tocantins & 0,039 \\
\hline Muricilândia & 0,003 & $120^{\circ}$ & Maurilândia do Tocantins & 0,039 \\
\hline Recursolândia & 0,002 & $121^{\circ}$ & Aragominas & 0,037 \\
\hline São Bento do Tocantins & 0,001 & $122^{\circ}$ & Paranã & 0,037 \\
\hline Juarina & 0,000 & $123^{\circ}$ & Muricilândia & 0,037 \\
\hline Itapiratins & $-0,001$ & $124^{\circ}$ & Esperantina & 0,036 \\
\hline São Salvador do Tocantins & $-0,002$ & $125^{\circ}$ & Praia Norte & 0,036 \\
\hline Sampaio & $-0,002$ & $126^{\circ}$ & Porto Alegre do Tocantins & 0,036 \\
\hline Campos Lindos & $-0,003$ & $127^{\circ}$ & Riachinho & 0,035 \\
\hline Cachoeirinha & $-0,004$ & $128^{\circ}$ & Carrasco Bonito & 0,035 \\
\hline Santa Maria do Tocantins & $-0,005$ & $129^{\circ}$ & Cachoeirinha & 0,031 \\
\hline Santa Terezinha do Tocantins & $-0,006$ & $130^{\circ}$ & Taipas do Tocantins & 0,028 \\
\hline Maurilândia do Tocantins & $-0,007$ & $131^{\circ}$ & São Sebastião do Tocantins & 0,028 \\
\hline Riachinho & $-0,008$ & $132^{\circ}$ & Barra do Ouro & 0,025 \\
\hline Palmeirante & $-0,012$ & $133^{\circ}$ & Abreulândia & 0,022 \\
\hline Lagoa do Tocantins & $-0,013$ & $134^{\circ}$ & Lavandeira & 0,022 \\
\hline Praia Norte & $-0,014$ & $135^{\circ}$ & São Félix do Tocantins & 0,020 \\
\hline Barra do Ouro & $-0,015$ & $136^{\circ}$ & Palmeirante & 0,014 \\
\hline Carrasco Bonito & $-0,017$ & $137^{\circ}$ & Recursolândia & 0,003 \\
\hline Mateiros & $-0,021$ & $138^{\circ}$ & Ponte Alta do Bom Jesus & 0,000 \\
\hline Esperantina & $-0,021$ & $139^{\circ}$ & Lizarda & $-0,005$ \\
\hline
\end{tabular}

Fonte: Resultados da pesquisa (2016).

\section{Artigo recebido em: 26/10/2015}

\section{Artigo aprovado em: 26/07/2016}

